GUZMÁN DALBORA, José Luis, “Mentalidad autoritaria, actitudes punitivas y

pensamiento penal: un esbozo"

Polít. crim. Vol. 14, № 27 (Julio 2019), Doc. 2, pp. 606-634

[http://politcrim.com/wp-content/uploads/2019/06/Vol14N27D2.pdf]

\title{
Mentalidad autoritaria, actitudes punitivas y pensamiento penal: un esbozo*
}

\section{Authoritarian mind, punitive attitudes and criminal thinking: an outline}

José Luis Guzmán Dalbora

Profesor titular de Derecho penal y de Introducción a la Filosofía moral y jurídica, Universidad de Valparaíso. Investigador responsable del Centro de Investigaciones de Filosofía del Derecho y Derecho penal (CIFDE)

joseluis.guzman@uv.cl

Resumen: El artículo repasa el concepto de autoritarismo en la Filosofía política y los conceptos de personalidad, carácter y actitudes autoritarias en la Piscología social. Con sus elementos comunes construye el concepto de mentalidad autoritaria. Este concepto permite ilustrar las actitudes punitivas de los profanos, pero también las inclinaciones fundamentales del pensamiento penal autoritario.

Palabras clave: Autoritarismo, Mentalidad autoritaria, Actitudes punitivas, Pensamiento penal.

Abstract: The article reviews the concept of authoritarianism in Political Philosophy and the concepts of authoritarian personality, authoritative character and authoritarian attitudes in Social Psychology. With its common elements, it constructs the concept of authoritarian mind. This concept allows to illustrate the punitive attitudes of the common citizen, but also the fundamental inclinations of the authoritarian criminal thinking.

Key words: Authoritarianism, Authoritarian mind, Punitive attitudes, Criminal thinking.

\section{El autoritarismo en la Filosofía política}

El autoritarismo presenta dificultades de definición y, en desquite - o para colmo-, también algún grado de polivalencia epistemológica. Pocas nociones han sido tan estudiadas en la Filosofía y Ciencia políticas como las de autoridad, poder y obediencia, claves para la inteligencia del autoritarismo en general, sin que, empero, reine verdadero consenso acerca de la delimitación de cada una y sus relaciones recíprocas. Estos condicionamientos complican el manejo que hacemos del concepto en la presente contribución, cuyo limitado objetivo es destacar su trascendencia para el pensamiento jurídico-penal y las actitudes del profano frente a los elementos universales del Derecho punitivo: delito y pena.

\footnotetext{
${ }^{*}$ Un esquema de este texto fue presentado como ponencia en las XV Jornadas Chilenas de Derecho Penal y Ciencias Penales, que tuvieron lugar en Santiago de Chile los días 21 a 23 de noviembre de 2018.
} 


\section{Polít. crim. Vol. 14, No 27 (Julio 2019), Doc. 2, pp. 606-634 [http://politcrim.com/wp-content/uploads/2019/06/Vol14N27D2.pdf]}

Como sea, no vamos a engolfarnos en aquellas controversias ni a seguir todos los hilos que se desprenden del autoritarismo o que convergen especulativamente en él. Para nuestros efectos bastará con retomar dos hebras, una que lo reconduce a la Filosofía política, otra que procura encasillarlo en la Psicología. Con la primera se sentirá más familiarizado el jurista, con la segunda, el criminólogo, aunque una aproximación intuitiva, apoyada en sus respectivas formaciones, pudiera no franquearles los componentes pluridimensionales que cela el escurridizo concepto. Por lo demás, el autoritarismo es un paradigma de la necesidad de integrar los conocimientos jurídico-penales y criminológicos. Enseña especialmente al penalista uno de las tantas manifestaciones de la doble dependencia de su disciplina científica, que yace en medio del plano de la Filosofía, a la que adeuda sus fundamentos ontológicos, metafísicos, epistemológicos y axiológicos, y el reservado a las ciencias de la naturaleza, con lo que nos referimos a los saberes que describen y explican las conexiones empíricas a partir de las cuales el dogmático puede elaborar los conceptos de su competencia. Sólo que esta manifestación en particular es realmente cardinal, ya que se inscribe en las relaciones del Derecho penal con el Derecho político, acerca de cuya importancia no es preciso extenderos por nuestra cuenta. ${ }^{1}$

Por lo pronto, en la Filosofía política el autoritarismo nos sale al paso como una suerte de «sistema» político. La denominación no es en sí misma certera, amén de que tampoco acota bien el contenido del argumento. La palabra sistema, de raigambre filosófica, posee un valor cognoscitivo, como el conjunto ordenado y completo de conocimientos acerca de un objeto o una serie de objetos homogéneos. ${ }^{2}$ Sin embargo, lo que está en juego en esta primera acepción del autoritarismo no son principios o reglas enlazados racionalmente entre sí, sino la entidad histórica de ciertas organizaciones políticas, expresado de otra manera, hechos colectivos antes que categorías conceptuales reconducidas a un principio unificador. Esto aparte, autorizadas voces del saber político reconocen que los regímenes autoritarios del pasado y el presente no parecen ser miembros de una misma especie, sino que consistirían en clases diferentes de un género impreciso, a lo sumo caracterizadas por algunos rasgos comunes, aunque ni siquiera éstos son de pacífica identificación entre los politólogos. $^{3} \mathrm{La}$ confusión ha posibilitado que en ocasiones se dé por sinónimos regímenes bien diferentes unos de otros, a los que se llama indistintamente dictadura, tiranía, despotismo o totalitarismo, en circunstancias que lo único que los mancomuna, al decir de un especialista, es designar "situaciones políticas de exacerbación y robustecimiento excesivo y excluyente del poder de dominación".

\footnotetext{
${ }^{1}$ Acometimos la tarea en nuestro libro Elementi di Filosofia giuridico-penale, a cura di Gabriele Fornasari y Alessandra Macillo, Napoli: Editoriale Scientifica, 2015, pp. 44-50, con glosa de los principales autores que se han ocupado del argumento. Parte de esas disquisiciones serán retomadas en el presente apartado.

${ }^{2}$ Cfr. RIVACOBA Y RIVACOBA, Manuel de, Elementos de Criminología, Valparaíso: Edeval, 1982, pp. 257 y 258 , donde distingue el concepto de los de método y plan.

${ }^{3}$ Véase, por ejemplo, DUVERGER, Maurice, Instituciones políticas y Derecho constitucional, Prólogo de LUCAS VERDÚ, Pablo, $5^{\text {a }}$ edición española, totalmente refundida, dirigida por Jorge Solé-Tura, Barcelona: Ediciones Ariel, Barcelona, 1970, pp. 371 y 372, donde se inclina por la oposición general del autoritarismo a la democracia liberal (rechazo del pluralismo, supresión de las elecciones, concentración del poder, ausencia de libertades y garantías públicas).

${ }^{4}$ RIVACOBA Y RIVACOBA, Manuel de, "Franco o el tirano. Ensayo de teoría política aplicada", «Umbral», Revista mensual de arte, letras y estudios sociales, París, n 29, mayo de 1964, pp. (4-6) 4, continuado en $\mathrm{n}^{\circ} 30$, junio de 1964, págs. 16-17, y n 31-32, julio y agosto de 1964, pp. 10-12.
} 
Problemas análogos suscita el autoritarismo en el terreno de las ideologías políticas ${ }^{5}$. Falta claridad acerca de las ideas básicas del autoritarismo sin más. Por este motivo, hay quienes piensan que sus contornos no lo diferencian rigurosamente de las ideologías totalitarias, con las que sólo compartiría la ambición de organizar la sociedad en términos jerárquicos, según una inspiración irracionalista y desigualitaria. ${ }^{6}$ En el círculo de la justicia punitiva esta heterogeneidad permite dar cuenta de las diversas tipologías de Derecho penal propuestas según sus influencias políticas, que van desde los criminalistas que distinguen Derecho penal autoritario y Derecho penal totalitario, a quienes consideran que el segundo sería sólo una variedad extrema de la actitud existencial cínica y frustrada que trasunta el primero. $^{7}$

Pese a ello, existen determinados rasgos que se repiten en toda organización, situación, ideología o, dado lo raro que se ha vuelto en nuestros días defender abiertamente un sistema de ideas de semejante catadura, simples pensamientos o exigencias de traza autoritaria. Son tres: a) la firme creencia en el poder de dominio de unos individuos sobre otros; b) la voluntad de obediencia incondicional a los que están arriba y de imponerse a los que están abajo, en una estratificación vertical más o menos imperfecta, porque la corroe la $\operatorname{arbitrariedad}^{8}$, y c) la convicción de que poder, obediencia e imposición responderían a un

\footnotetext{
${ }^{5}$ Aunque la índole de las ideologías debiera devolverlo a la teoría, el autoritarismo no podrá consistir en una especulación pura, porque a ésta son refractarios los fines prácticos de toda política que no consista en una utopía. Se repite en lo ideológico el mismo inconveniente de los regímenes políticos, cuyas clasificaciones, desde las clásicas de Platón, Aristóteles, Maquiavelo, Montesquieu, etc., hasta las usuales en los libros modernos de teoría política, reflejan realidades que se dieron en la historia de los pueblos. Todo lo demás es utopía, un puro funcionamiento de la razón sin ningún momento o contenido empírico, como explica RIVACOBA Y RIVACOBA, Manuel de, Aproximación a Utopía, Santiago de Chile: Instituto de Chile, 1985, cfr. p. 15.

${ }^{6}$ STOPPINO, Mario, voz Autoritarismo, en el Diccionario de política dirigido por BOBBIO, Norberto, MATTEUCCI, Nicola, y PASQUINO, Gianfranco, nueva edición enteramente revisada y ampliada, con redacción española de ARICÓ, José, SOLER, Martí, y TULA, Jorge, México: Siglo Veintiuno, 14ª ed., 2005, t. I, cfr. pp. 125-136, pp. 126 y 127.

${ }^{7}$ Anotamos esta discrepancia en nuestro viejo artículo GUZMÁN DÁLBORA, José Luis, "Relaciones del Derecho penal con el Derecho constitucional, y su concreción en la Constitución política chilena (1980)", Anuario de Filosofía Jurídica y Social, publicación de la Sociedad Chilena de Filosofía jurídica y Social, Valparaíso: Edeval, $\mathrm{n}^{\circ} 12$, 1994, pp. (165-199) 173. Del primer parecer, RIVACOBA Y RIVACOBA, Manuel de, "Orden político y orden penal", Revista Chilena de Derecho, Facultad de Derecho de la Pontificia Universidad Católica de Chile, vol. 22, n ${ }^{\circ} 2$ (monográfico: «Derecho penal y Criminología»), mayo-agosto de 1995, pp. (201-212) 204, 206 y 208. Del segundo, ZAFFARONI, Eugenio Raúl, Tratado de Derecho penal, Parte general, 5 vols., Buenos Aires: Ediar, t. II, 1987, pp. 391-392, y, con fundamentos diferentes (crueldad punitiva y despreocupación por los derechos del hombre en la solución autoritaria), JIMÉNEZ DE ASÚA, Luis, Tratado de Derecho penal, publicados, 7 vols., Buenos Aires: Editorial Losada, $2^{a}$ ed., t. II, 1950, p. 166.

${ }^{8}$ En efecto, el arribismo cínico, el nepotismo y el favoritismo pueden hacer de la excepción personal una regla incluso en regímenes totalitarios monolíticos como los comunistas, con su caterva de aprovechados y logreros. Sin embargo, esta formación de castas, que contradice la igualdad de los ciudadanos proclamada por la ideología comunista, confirma el primer rasgo del autoritarismo. En estos regímenes "el motor de la vida social no es la fe en un ideal, sino la voluntad de poder". TODOROV, Tzvetan, La experiencia totalitaria, Trad. de SOBREGUÉS, Noemí, Barcelona: Galaxia Gutemberg, 2014, p. 27. Sobre la corrupción de los altos dignatarios del Partido Nacional Socialista Obrero Alemán incluso antes de la toma del poder en 1933, véase KERSHAW, Ian, Hitler, Trad. de FONTAL, Yolanda y SARDIÑA, Carlos, Barcelona: Ediciones Península, 2015, pp. 317-318.
} 


\section{Polít. crim. Vol. 14, No 27 (Julio 2019), Doc. 2, pp. 606-634 [http://politcrim.com/wp-content/uploads/2019/06/Vol14N27D2.pdf]}

orden natural en los asuntos humanos, tan natural como la desigualdad de los hombres, discriminados por la parcialidad autoritaria con arreglo a la infinitud de las condicionalidades empíricas de cada cual, en lugar de reunirlos según un principio sintético presente en todos. ${ }^{9}$ Sobre la inversión del vínculo entre humanidad y hombre, de la definición de lo generalmente humano por lo que es específico en cada quien - hecho lo cual cada autoritarismo queda libre de colmar la nota general con las identidades grupales de su preferencia (religiosas, raciales, nacionales, económicas, sociales, etc.)—, se yerguen dócilmente las capas superiores del afán de dominio, el deseo de obedecer al dominador y la tendencia a despreciar al dominado.

Este es el autoritarismo político visto desde abajo, reserva hecha de que la raíz empírica de la mentalidad autoritaria hinca mucho más hondo, como se dirá en el apartado siguiente. Pero el autoritarismo político puede ser ilustrado desde arriba, contemplándole con la ayuda de la filosofía de los valores.

Los sistemas axiológicos conocen el absolutismo valorativo. Lo característico del valor absoluto es su validez universal, nacida de lo incondicionado y tendente a una obligatoriedad sin límites de espacio, tiempo y personas. Su culminación es la unidad estimativa y la objetividad de los valores. Ahora bien, el absolutismo valorativo se proyecta en concepciones jurídicas y en las ideologías políticas correlativas. Desenlace jurídico del absolutismo son visiones supraindividualistas y transpersonales que colocan a la totalidad (el Estado, la raza, la nación, etc.) como sujeto de fines. Su metáfora social es un organismo en que el todo no existe a causa de las partes, sino los miembros a causa del todo, y su idea del Derecho es el poder. ${ }^{10}$ En seguida, supraindividualismo y traspersonalismo hallan cauce político en el autoritarismo, el gobierno del poder de dominación. El autoritarismo deposita su fe en ésta, nunca en el concepto de autoridad. ${ }^{11}$ Por lo mismo, cercena los derechos políticos, ya que perjudican el poder estatal; combate los derechos individuales, que debilitan a la organización que se busca mantener; se defenderá de cualquier asomo de ataque, aun de las simples ideas que a su juicio pudieran conmover su superioridad. No es indispensable descender a ulteriores detalles en pos de una caracterización cabal del

\footnotetext{
${ }^{9}$ El autoritarismo invierte la relación de la humanidad con el hombre. La humanidad, proyectada en cada persona, se traduce en una identidad universal, aquello en que nos parecemos a los demás, "nuestra identidad como seres humanos", que "nos recuerda que somos iguales a todos". Esta igualdad no es conmovida por nuestra identidad personal. Al contrario, el hombre la necesita precisamente porque es desigual o diferente de todos los demás, sea por su destino biológico particular, el entorno familiar, social y cultural en que creció, sus convicciones y, en general, el sentido que asigna a la vida. Precisa de esa identidad universal justamente para su identidad personal, esa que lo hace igual a sí mismo y diferente de todos sus congéneres. Véase SQUELLA NARDUCCI, Agustín, Igualdad, Valparaíso: Editorial de la Universidad de Valparaíso, 2014, pp. 48 y 49 , del que tomamos las frases entrecomilladas.

${ }^{10}$ Cfr. RADBRUCH, Gustav, Filosofía del Derecho, Trad. de MEDINA ECHEVARRÍA, José, Madrid: Editorial Revista de Derecho Privado, $3^{\text {a }}$ ed., 1952, pp. 73-80, y LÓPEZ, Mario Justo, Introducción a los estudios políticos, 2 vols., Buenos Aires: Ediciones Depalma, t. I, 1983, pp. 226, 234 у 235.

${ }^{11}$ Con la autoridad ni siquiera comparte el significado del étimo latino augeo, que implica producir algo desde el propio seno, crear, hacer existir, todo lo contrario de la infertilidad autoritaria y su inclinación a unificar, homogenizar, aplanar la sociedad. Cfr. AGAMBEN, Giorgio, Estado de excepción. Homo sacer, II, I, Trad. de COSTA, Flavia, y COSTA, Ivana, con introducción y entrevista de Flavia Costa, Buenos Aires: Adriana Hidalgo Editora, 2007, p. 140, y TODOROV, op. cit. nota n ${ }^{\circ}$ 8, p. 20. A lo sumo, la labor de acrecentamiento del autoritarismo político consiste en aumentar lo que ya existe, el poder.
} 
fenómeno, ya que todos los elementos que cabría invocar para redondearlo constituyen un sistema único. En efecto, "no hay que comenzar preguntándose cómo se comportarán los conservadores en una cuestión constitucional o jurídica, porque siempre adoptarán aquella decisión que contribuya a conservar o aumentar el poder del Estado". ${ }^{12}$

Ora observado desde arriba, ora derivado desde abajo, el autoritarismo en la Filosofía política nos ofrece, por decirlo así, una unidad de formas - la tricotomía poder, obediencia y desigualdad-, mas no una unidad de contenidos ideológicos ni de organizaciones políticas. Por eso ha podido conjugarse con doctrinas de diferente signo, como también cristalizar en regímenes de todo jaez, sin excluir los democráticos, que están permanentemente expuestos al riesgo de la perversión autoritaria. ${ }^{13}$ De momento, procuraremos unir la transmutación que ésta practica de los conceptos de humanidad y hombre, esto es, el autoritarismo político visto desde abajo, con las raíces psicológicas de la personalidad, las creencias y actitudes que le son congruentes.

\section{El autoritarismo en la Psicología}

El interés psicológico por el autoritarismo se remonta a la primera mitad del siglo XX, cuando recibió el estímulo desencadenante de concretas realidades políticas, pero su trayectoria siguió la evolución de la Psicología. Allende las críticas que han merecido las teorías fraguadas desde entonces, el hecho es que el concepto se ha instalado como un tema permanente de investigación en esta ciencia, principalmente su segmento de psicología social. $^{14}$

Llamará la atención que un concepto socialmente condicionado como este despierte atención en un saber que versa de la conducta del hombre, sus experiencias íntimas y las relaciones entre la esfera psíquica y el comportamiento individual. No obstante, así como nuestro concepto es incomprensible sin referirlo a la vida colectiva, así también la Psicología no deja de estudiar los efectos de las actitudes del individuo frente a otros, con las interacciones resultantes. De antiguo fue observado que si toda Psicología es individual, porque su objeto es la vida anímica del sujeto, tiene también que habérselas con tipos

\footnotetext{
12 "Por la misma razón son partidarios de la pena de muerte, de la política de armamentos y de las conquistas guerreras: fortalecimiento de los instrumentos de poder del Estado". MAYER, Max Ernst, Filosofía del Derecho, Trad. de la $2^{\mathrm{a}}$ edición original por LEGAZ LACAMBRA, Luis, Barcelona: Editorial Labor, 1937, pp. 161-162.

${ }^{13}$ El autoritarismo semeja a una Hidra, y de ahí que quepa hallarle desde en las variedades extremas del totalitarismo, no importa si negro, pardo o rojo, hasta en democracias gobernadas por poderes extrajurídicos, que hoy son principalmente poderes económicos. Como enseña la historia reciente, las democracias han cedido a la creencia en unas supuestas leyes de la naturaleza o de la historia que legitimarían el Derecho positivo, al desarrollo práctico de la lógica o dialéctica del pensamiento ideológico y a formas de gobierno cuya esencia es el terror y el aislamiento de los seres humanos. Cfr. ARENDT, Hanna, Los orígenes del totalitarismo, versión española de SOLANA, Guillermo, Madrid: Taurus, 1968, pp. 560, 561, 569, 572 y 574. De las derivaciones antidemocráticas, por tanto, autoritarias, de las actuales sociedades capitalistas, tratan extensamente FERRAJOLI, Luigi, y ZOLO, Danilo, Democracia autoritaria y capitalismo maduro, prólogo de IBÁÑEZ, Perfecto Andrés, Barcelona: Colección El Viejo Topo, 1980, pp. 23-24, 39, 55 y 56.

14 "El concepto de autoritarismo parece seguir plenamente vigente para explicar ciertas actitudes y comportamientos políticos que suponen una amenaza continua para los valores de tolerancia, libertad, respeto a la diferencia, etc." SABUCEDO CAMESELLE, José Manuel, Psicología política, Madrid: Editorial Síntesis, 2010, p. 45.
} 


\section{Polít. crim. Vol. 14, No 27 (Julio 2019), Doc. 2, pp. 606-634 [http://politcrim.com/wp-content/uploads/2019/06/Vol14N27D2.pdf]}

determinados de personalidad revelados por la congruencia y conexión de ciertos rasgos individuales. ${ }^{15}$ La propia noción de personalidad atañe a caracteres generales humanos, que se descubren al investigador por encima de los trazos caracterológicos de cada individuo, en el influjo que ejerce en las personas el mundo circundante, la huella que les imprime la vivencia subjetiva de sus circunstancias. Y entre tales circunstancias hay algunas capaces de contribuir a la formación de una personalidad autoritaria.

Por cierto, el concepto de personalidad autoritaria es apenas uno de los pliegues de la pesquisa del tema en la Psicología, siquiera el único relativamente noto para el profano. La psicología de la personalidad, que estudia los rasgos caracterológicos, la estructura de la personalidad y los métodos con que diagnosticarla ${ }^{16}$, tiene una expresión prototípica en el psicoanálisis. Con todo, las investigaciones pioneras en este campo, de las que pronto haremos sucinto mérito, combinaron el enfoque teórico del psicoanálisis con metodologías de psicología social. Es más, en el tránsito que llevó desde la psicología estrictamente individual a la psicología social, fue de por medio el enriquecimiento del concepto de carácter, básico en aquélla, con el concepto de personalidad, aportado por ésta. La psicología del individuo tenía que estar cifrada en el carácter, eso es, la totalidad de las posibilidades reactivo-afectivas de un individuo, condicionadas por un fondo hereditario y el destino que le tocó vivir, la coloración que asumieron desde tal fondo somático las vivencias. El carácter representa el sello anímico de cada hombre, expresa su unicidad y peculiaridad como individuo, por cuyo motivo ha de permanecer inmutable y morir con el organismo que lo formó. ${ }^{17}$ Por su parte, la psicología social, que se ocupa de los fenómenos psicológicos de interacción humana, esto es, las condiciones colectivas que determinan la forma y el contenido de la acción del hombre ${ }^{18}$, maneja de preferencia el concepto de personalidad, que suma a los estímulos internos de estampa caracterológica los rasgos adquiridos por obra del ambiente y la cultura en general. La personalidad viene a ser así el conjunto de disposiciones biológicas, innatas, los impulsos, apetitos e instintos del individuo, así como las tendencias y disposiciones adquiridas. ${ }^{19}$ No está grabada para siempre, sino que se va esculpiendo en él, admite tipologías mucho más variadas que las que franquea el carácter, puede albergar especies modeladas por condicionamientos sociales y, en fin, su conocimiento no es obtenido mediante observación directa, porque estas cualidades se infieren de las conductas que las manifiestan. ${ }^{20}$

\footnotetext{
${ }^{15}$ VON ASTER, E., Introducción a la Psicología, Trad. de la $2^{\text {a }}$ edición alemana por LANDA, Rubén, Barcelona: Editorial Labor, $3^{\text {a }}$ ed., 1935, cfr. pp. 27 y 28.

${ }^{16}$ WOLF, Werner, Introducción a la Psicología, Trad. de Pascual del Roncal, Federico, México: Fondo de Cultura Económica, 1969, cfr. p. 328.

${ }^{17}$ ROHRACHER, H., Introducción a la caracterología, Trad. del alemán de LUZURIAGA, Lorenzo, Buenos Aires: Editorial Losada, $3^{\text {a }}$ ed., 1958, cfr. pp. 11, 14 y 190 a 195. Véase, también, LERSCH, Philipp, La estructura de la personalidad, con revisión y estudios preliminares de SARRÓ, Ramón y Trad. de SERRATE TORRENTE, A., Barcelona: Editorial Scientia, 1966, p. 41.

${ }^{18}$ Con mayor precisión, son las condiciones que determinan las actitudes de una persona, los efectos de tales actitudes en su contacto con otras y las condiciones que conducen a interrelaciones de competencia o cooperación. Cfr. DEUTSCH, Morton, y KRAUSS, Robert M., Teorías en psicología social, versión castellana de ZEIGNER, Silvia, Barcelona: Editorial Paidós, 1980, pp. 14-15.

${ }^{19}$ Wolf, op. cit. nota ${ }^{\circ} 16$, cfr. p. 296.

${ }^{20}$ LINTON, Ralph, Cultura y personalidad, Trad. de Javier Romero, México: Fondo de Cultura Económica, 1978, p. 94.
} 
Ahora, entre los índices de la personalidad figuran las actitudes, concepto de psicología social que designa un sistema estructurado y duradero de componentes cognoscitivos, sentimentales y afectivos que hacen al individuo evaluar positiva o negativamente los sucesos del mundo exterior y son un factor decisivo de las conductas correlativas. ${ }^{21}$ Las distintas actitudes no yacen aisladas entre sí, sino que forman grupos de conexión. Además, son una pieza del complejo mosaico de las creencias, otro concepto de psicología social, con el que se alude a un cuerpo organizado de informaciones, actitudes y convicciones que giran alrededor de valores o cosas consideradas importantes en un grupo social. Como las actitudes, las creencias están formadas por elementos cognoscitivos, afectivos y evaluativos. Determinan las preferencias de su portador y, en definitiva, su conducta. ${ }^{22}$

Pues bien, estos tres conceptos psicológicos, personalidad, actitud y creencia, han sido aplicados al problema del autoritarismo. En la psicología social se ha hablado de personalidades, actitudes y creencias autoritarias (aunque también dogmáticas, cerradas, conservadoras), como resumimos a continuación. ${ }^{23}$

El punto de partida de estas investigaciones se remonta a representantes conspicuos de la antigua Escuela de Frankfort, que aplicaron al asunto las categorías del psicoanálisis. En la Psicología de masas del fascismo (1933), Wilhelm Reich discurre todavía de un carácter autoritario nacido de la represión sexual en la infancia y la sumisión del niño al poder del padre, cuya manifestación en el individuo adulto, tener la mirada dirigida siempre hacia los que están más arriba, en una actitud pasiva y obediente, abundaba entre los miembros de la pequeña burguesía alemana de la época. La mentalidad reaccionaria resultante es asociada por el autor a un «miedo a la libertad» ${ }^{24}$, el mismo que da el título a la conocida monografía

${ }^{21}$ Cfr. KRECH, David, CRUTCHFIELD, Richard S., y BALLACHEY, Egerton L., Psicología social, Trad. del inglés de ÁLVAREZ VILLAR, Alfonso, Madrid: Biblioteca Nueva, 2a ed., 1972, pp. 157 a 206 , y D'ADAMO, Orlando y GARCÍA BEAUDOUX, Virginia, "Actitudes y conducta (actitudes políticas)", en la obra colectiva coordinada por MORALES, J. Francisco, PÁEZ, Darío, KORNBLIT, Ala Lía, y ASÚN, Domingo, Psicología social, Buenos Aires: Prentice Hall-Pearson Educación, 2002, pp. 287-307, 287, 288, 290 y 295.

${ }^{22}$ Cfr. YOUNG, Kimball, Psicología social de la personalidad, versión castellana de CALDERÓN, Irma, Buenos Aires: Editorial Paidós, 1969, pp. 221 a 224, y D’ADAMO y GARCÍA BEAUDOUX, en op. cit., nota $\mathrm{n}^{\circ} 21$, pp. 292 y 293. En esta última página los autores explican que las creencias son elementos cognitivos que permiten unir los valores generales de un individuo con sus actitudes y opiniones ante una cuestión concreta. Fue sumamente certera la intuición del concepto en ORTEGA Y GASSET, José, Ideas y creencias, Madrid: Espasa-Calpe, 8 ${ }^{\mathrm{a}}$ ed., 1976, cfr. pp. 17 a 41, quien consideró las creencias como implicaciones latentes del pensamiento, pero que ejercen máxima influencia en la conducta y la vida intelectual propiamente dicha.

${ }^{23}$ Nótese que la investigación del autoritarismo es reclamada también por la psicología política, un sector de la psicología social, por lo cual citamos indistintamente bibliografía de entrambas. Cfr., de momento, SEOANE, Julio, y RODRÍGUEZ, Ángel, Psicología política, Madrid: Ediciones Pirámide, 1988, pp. 20, 21 y 22, y ÁlVARO, José Luis, GARRIDO, Alicia, y TORREGROSA, José Ramón, Psicología social aplicada, Madrid: MacGraw-Hill, 1996, pp. 221 y ss. Asimismo, su estudio interesa a la Sociología, y el propio concepto podría ser incardinado en los fenómenos psíquicos totales de que discurre GURVITCH, Georges, en Tratado de Sociología, t. II, traducción de EGUIBAR, María C. revisada por DUJOVNE, León, Buenos Aires: Editorial Kapelusz, 1963, pp. 393-398.

${ }^{24}$ REICH, Wilhelm, Psicologia di massa del fascismo, Trad. de BELFIORE Furio y WOLF, Annelise, Milano: SugarCo Edizioni, 1982, cfr. pp. 62, 63, 64, 80, 86, 87, 92 y 93. Véase al respecto SANGRADOR GARCÍA, José Luis, "La personalidad autoritaria”, en el volumen coordinado por JIMÉNEZ BURILLO, 


\section{Polít. crim. Vol. 14, No 27 (Julio 2019), Doc. 2, pp. 606-634 [http://politcrim.com/wp-content/uploads/2019/06/Vol14N27D2.pdf]}

de Erich Fromm, posterior en siete años. Fromm continúa anclado al sedimento de psicología individual del psicoanálisis, lo cual, empero, no le impide presentar una descripción general del significado de la libertad para el hombre contemporáneo. Pareciera que a éste, mientras más gana en libertad, más lo hiere un sentimiento de inseguridad, el que puede ser compensado a través de ciertos mecanismos de evasión, entre los que Fromm describe en primer lugar el autoritarismo. Consiste en la tendencia a abandonar la autonomía del yo para fundirse con algo o alguien exterior a la individualidad del sujeto, del que espera adquirir las fuerzas de que carece. Su forma nítida de manifestación yace en una tendencia compulsiva sadomasoquista hacia dominar y someterse, bajo la que se esconde la médula del «carácter autoritario», una actitud de fascinación y obsecuencia ante el poder, quien quiera lo encarne - porque este tipo caracterológico lo sigue y defiende, no a causa de los valores que pudiera representar, sino por el mero hecho de ser poder-, y de desprecio hacia las personas desprovistas de él, a las que atacará, humillará y tratará de dominar. El núcleo del carácter autoritario, pues, es un trasunto perfecto del miedo a la libertad y, en definitiva, al yo responsable de sí. Por eso, quien lo padece preferirá someterse al destino, a la fatalidad, a fuerzas exteriores racionalizadas como ley natural, en un ambiente gobernado por la impotencia del individuo, la desigualdad de los demás y el sometimiento a los jefe ${ }^{25}$, como en las figuras literarias, pero de total realismo, trazadas por Joseph Roth en La marcha Radetzky y Heinrich Mann en sus novelas El súbdito y La cabeza. $^{26}$

El paso del psicoanálisis a la psicología social lo dio en 1950 el grupo de investigadores encabezados por Theodor Adorno y R. Nevitt Sanford en el célebre estudio $L a$ personalidad autoritaria, cuyos vínculos con los adelantos de Reich y Fromm son

Florencio, Psicología de las relaciones de autoridad y poder, Barcelona: Editorial UOC, 2006, pp. 127-165, 130.

${ }^{25}$ FROMM, Erich, El miedo a la libertad, Trad. de GERMANI, Gino, Buenos Aires: Paidós, 1993, cfr. pp. 22, 141, 142, 146, 168, 169, y 170 a 173. Además, OVEJERO BERNAL, Anastasio, "El autoritarismo: enfoque psicológico", El Basilisco, número 13, noviembre de 1981-junio de 1982, cfr. pp. 40-44, 40-41.

${ }^{26}$ Diederich Hessling, el personaje central de El súbdito, se sentía feliz por pertenecer a una totalidad impersonal, fuese el instituto, el ejército o el propio imperio alemán. "Correspondía a sus impulsos pasar por la vida no como persona, sino corporativamente, como miembro de un estamento", y, por cierto, le cautivaba el poder, "que cabalga por encima de todos nosotros y cuyos cascos besamos", "que llevamos en la sangre, porque en ella llevamos sumisión", viviendo "sin piedad hacia quienes se alejan de él, triunfando aunque nos destruya: pues así justifica él nuestro amor". Este tipo humano fue el que siguió ciegamente a los líderes irresponsables que desde la política, la ciencia, la industria pesada, la milicia y las asociaciones nacionalistas condujeron a Alemania al horror de la Primera Guerra Mundial. Las citas de El súbdito las recogemos de la versión castellana de LÓPEZ Y LÓPEZ DE LIZAGA, José Luis, Madrid: Edafsé, 2002, pp. 51 y 58. Para el trasfondo histórico de Der Kopf, «novela del dirigente», es muy recomendable el comentario conclusivo de ANGER, Sigrid, en MANN, Heinrich, Die Armen. Der Kopf. Zwei Romane, Düsseldorf: Claassen Verlag, 1988, pp. 673-692.

Por su parte, en la novela del escritor austríaco no es casual que la decadencia de la monarquía austrohúngara tenga como punto de arranque la subordinación que padres y superiores inculcaban a hijos e inferiores, "la obediencia ciega que todo subordinado debe prestar a sus jefes, así como todo inferior a su superior". ROTH, Joseph, La marcha Radetzky, Trad. de QUINTANA, Arturo, Barcelona: Edhasa, 2008, p. 46. 
debidamente destacados en un segmento decisivo de esta extensa obra. ${ }^{27}$ Conceptos básicos de la teoría de Freud sobre la estructura de la psiquis humana se enriquecen con metodologías cualitativas de psicología clínica y mediciones cuantitativas de psicología social. De hecho, los autores emplean como eje conceptual, ya no el carácter, sino la personalidad, entendida como una organización más o menos estable de fuerzas o necesidades psíquicas (pulsiones, deseos, impulsos emocionales), que varían de un individuo a otro en cualidad, intensidad, gratificación y objeto, e interactúan entre sí. Estas fuerzas representan disposiciones para la conducta, que condicionan asimismo las preferencias ideológicas del sujeto. La personalidad, empero, se va forjando a lo largo de la vida, bajo el impacto del medio social, que modela su núcleo, unido con particular hondura a las influencias recibidas durante la infancia en el entorno familiar. ${ }^{28}$

La hipótesis principal de este estudio es que "las convicciones políticas, económicas y sociales de un individuo forman con frecuencia un patrón amplio y coherente, como si estuviesen unidas por una «mentalidad» o «espíritu», y que este patrón es expresión de profundas tendencias de su personalidad". ${ }^{29}$ La personalidad autoritaria surgiría a causa de métodos de disciplina severos y rígidos usados en el niño por sus padres, quienes hacen depender su afecto y aprobación de la obediencia incondicional del vástago. Amén de resaltar en éste sólo los deberes y obligaciones, le infunden una excesiva conciencia de la diversidad de status en sus relaciones con otros, con aprecio hacia los que están arriba y desdén por los demás. Todo esto provoca en el rapaz una hostilidad larvada contra los padres $\mathrm{y}$, en general, las personas constituidas en autoridad, rivalidad que es objeto de represión y, luego, de un proceso de identificación con los superiores y de desplazamiento de las tendencias agresivas hacia grupos externos (individuos dotados de otra identidad personal o pertenecientes a los estamentos inferiores de la sociedad). El miedo a los impulsos reprimidos determina finalmente una organización tiesa de la personalidad, que evita la introspección y, antes bien, abunda en pensamientos estereotipados de condena a toda práctica que no se ajuste a los valores convencionales introyectados. Semejante personalidad, con sus necesidades psicológicas, sería la más propincua a las ideologías fascistas, que en la época del estudio de Berkeley habían demostrado ser la mayor amenaza contra los valores de la democracia. ${ }^{30}$

Los índices de la personalidad autoritaria fueron desplegados en unas escalas de medición de actitudes, una de las cuales permitía calibrar la propensión al fascismo. En esta escala se agrupó nueve variables (convencionalismo, sumisión, agresión, antiintracepción,

\footnotetext{
${ }^{27}$ ADORNO, Theodor, FRENKEL-BRUNSWIK, Else, LEVINSON, Daniel J., y SANFORD, R. Nevitt, The Authoritarian Personality, New York: Harper \& Row, 1950, cfr. p. 231. En adelante, para comodidad del lector, las citas serán tomadas de la fuente española citada en la nota siguiente.

${ }^{28}$ ADORNO, Theodor, Escritos sociológicos, II, primera Parte, edición de TIEDEMANN, Rolf, Trad. de GONZÁLEZ RUIZ, Agustín, Madrid: Ediciones Akal, 2009, cfr. pp. (147-527, que contienen los Estudios sobre la personalidad autoritaria) 158 y 159.

${ }^{29}$ ADORNO, op. cit. nota ${ }^{\circ} 28$, pág. 153.

${ }^{30}$ Prescindiendo de la relación de la personalidad autoritaria con el fascismo, asunto que tocamos dentro de poco en esta secuencia histórico-ideológica, parece ser una conquista permanente de la investigación de este tipo de personalidad su dependencia de la sumisión, disciplina severa y carencias afectivas impuestas al autoritario típico durante la infancia. Cfr. EBENSTEIN, William, Pensamiento político moderno, versión española de LÓPEZ, Dolores, y CERVERA, Vicente, bajo la dirección de TIERNO GALVÁN, Enrique, Madrid: Taurus Ediciones, 1961, p. 212.
} 
superstición y estereotipo, poder y dureza, destructividad y cinismo, proyectividad y sexo), de las que nos interesan especialmente dos. ${ }^{31}$ La sumisión implica una actitud dócil, obediente y acrítica respecto de autoridades fuertes, llámense líder, Estado o como se quiera. Por su parte, la agresión autoritaria consiste en la tendencia a rechazar, condenar y castigar a las personas que violan o son sospechosas de violar los valores convencionales. Toda la aversión reprimida del autoritario, una enemistad originalmente inculcada por y dirigida contra las autoridades familiares o sociales, cambia de foco en el adulto, para concentrarse en los grupos marginales, una proyección tanto o más exitosa cuando las propias autoridades públicas aprueban o fomentan estas formas de agresión. ${ }^{32}$ En semejante patrón, formado evidentemente por elementos masoquistas y sádicos de carácter inconsciente, intervienen además algunos ingredientes ideológicos de corte formal, "que contribuyen, por su propio impulso, a las personalidades reaccionarias y potencialmente fascistas". 33 Una tríada de tales componentes merece mención particular, a saber, la ignorancia, el estereotipo y la personalización. Los sujetos de puntaje más alto en la escala se caracterizan por un profundo desconocimiento de las cuestiones políticas, por cuya razón hablan sobre lo que no saben, aunque tampoco parece que se interesen en general por penetrar intelectualmente en el mundo tal como es, en lugar de lo cual "están dispuestos a aceptar información superficial o distorsionada en la medida que ésta confirme el mundo en el que ellos quieren seguir viviendo". ${ }^{4}$ Pensamiento estereotipado y personalización son sucedáneos cognoscitivos, medios con que aliviar la desorientación y ansiedad generadas por la ignorancia o el conocimiento superficial de las cosas. El estereotipo, la tirantez de dicotomías como "bueno y malo" o "nosotros y ellos", se remontan a fases tempranas de la niñez. En el adulto, en cambio, el estereotipo demanda personalización, "la tendencia a describir los procesos sociales y económicos objetivos, los programas políticos, las tensiones internas y externas en términos de alguna persona identificada con el caso en cuestión antes que tomándose la molestia de realizar las operaciones intelectuales impersonales requeridas por el carácter abstracto de los procesos sociales mismos". $35 \mathrm{Al}$ contentarse con ideas preconcebidas, rígidas y de omnipotencia mágica, a estas personalidades escapa completamente una comprensión objetiva de la realidad.

No pertenece al ámbito de nuestra competencia científica la tasación de las críticas que recibió prontamente la teoría de Adorno y Sanford, quienes vieron cuestionada tanto su metodología como la identificación entre personalidad autoritaria e ideologías de extrema derecha $^{36}$, pese a lo cual ha permanecido en pie a lo menos en el ligamen que estableció

\footnotetext{
${ }^{31}$ ADORNO, Theodor, Escritos sociológicos, cit. nota ${ }^{\circ}$ 28, cfr. p. 196.

32 Ídem, cfr. pp. 200 a 203. Véase, además, ORTIZ ZABALA, Milagros, Relaciones empíricas entre personalidad, autoritarismo y valores, Murcia: Secretariado de Publicaciones e Intercambio Científico, Universidad de Murcia, 1985, pp. 23 y 24.

${ }^{33}$ ADORNO, Theodor, cit. nota $\mathrm{n}^{\circ} 28$, p. 342.

${ }_{34}^{34}$ ADORNO, Theodor, cit. nota $\mathrm{n}^{\circ} 28$, p. 350.

${ }^{35}$ ADORNO, Theodor, cit. nota $\mathrm{n}^{\circ} 28$, p. 354.

${ }^{36}$ Una vasta bibliografía expone tales críticas, por ejemplo, DEUTSCH y KRAUSS, op. cit. nota $\mathrm{n}^{\circ} 18$, cfr. pp. 153 y 154; GARCÍA JURADO, Roberto, "La personalidad autoritaria y la cultura cívica: de Adorno a Almond y Verba", Revista Mexicana de Ciencias Políticas y Sociales, vol. XLIX, número 201, septiembre diciembre de 2007, cfr. pp. 13-30, pp. 16-17; MURGA FRASSINETTI, Antonio, "Teodoro Adorno y la personalidad autoritaria. Una lectura a 50 años de su publicación”, en la revista Argumentos, números 46-47, diciembre de 2003-abril de 2004, cfr. pp. 139-156, pp.151 y152; SANGRADOR GARCÍA, en op. cit. nota ${ }^{\circ}$ 24, cfr. pp. 138-145, y SABUCEDO CAMESELLE, op. cit. nota $\mathrm{n}^{\circ} 14$, cfr. pp. 48-51.
} 
entre antisemitismo, etnocentrismo y fascismo, luego confirmado por otros estudios. ${ }^{37} \mathrm{El}$ hecho es que nuevas inquietudes políticas, ahora volcadas hacia el problema del comunismo, y el hallazgo sociológico de tendencias autoritarias, intransigentes y extremistas en la clase trabajadora ${ }^{38}$, dejaron su impronta en la progresión del tema en la psicología social de la segunda mitad del siglo XX. Las principales teorías de los años sucesivos intentan desprender el concepto de personalidad autoritaria de contenidos ideológicos y, en su lugar, examinarlo como una variable de actitudes o bien como una estructuración de creencias. Entre ellas, son de relevancia para nuestra perspectiva los sistemas bidimensionales de Hans Jürgen Eysenck (1954) y Milton Rokeach (1960). ${ }^{39}$

El psicólogo alemán emigrado en Inglaterra propuso en el libro The Psychology of politics que el comportamiento político podía ser distribuido según dos polos de actitudes, que representan a su vez sendas dimensiones independientes de análisis de la personalidad. El primero contrapone la actitud conservadora a la actitud radical: aquélla propensa al patriotismo, la santificación de las fiestas, la pena de muerte, el trato duro a los criminales en general, la creencia en lo inevitable de la guerra y la realidad de Dios; ésta, proclive al comunismo, el pacifismo, control de los nacimientos, divorcio, libertad sexual, etc. ${ }^{40}$ La segunda dimensión separa dos tipos de mentalidad, una dura y otra blanda, que Eysenck recogió de la tipología de temperamentos enunciada en 1907 por William James. El individuo de mentalidad dura se caracteriza por ser empírico, sensacionalista, materialista, pesimista, irreligioso, fatalista y escéptico. Es dominado por valoraciones realistas, temporales y egoístas, contrariamente al ambiente altruista que reina en una mentalidad blanda, con sus rasgos de racionalismo, idealismo, optimismo, etc. ${ }^{41}$ Ahora, lo sobresaliente en la teoría es que estas dos dimensiones son perpendiculares entre sí, de lo que se sigue que la tipología mentalidad blanda o dura puede presentarse así en conservadores que en radicales, quienes sólo diferirían en el contenido ideológico de sus creencias. En todo caso, insistamos en que no son escalas que quepa superponer libremente. Eysenck relevó matices que aparecen al comparar rasgos de la mentalidad dura con las ideologías políticas extremas, sean éstas conservadoras o radicales. Así, agresividad y dominación, elementos

${ }^{37}$ FÜLLER, Anna, Kritischen Theorie und die Studien zur Authoritarian Personality, Norderstedt: Grin Verlag, 2005, cfr. p. 7-9, donde se dice, pensamos que con razón, que la validez de la escala F de Adorno para medir tendencias fascistas en un sujeto no implica que sea apropiada, además, para abarcar tendencias autoritarias en general (p. 9).

${ }^{38}$ La obra de cita obligada al respecto pertenece a LIPSET, Seymour Martin, El hombre político (1960), Trad. por MENDELEVICH, Elías, Buenos Aires: EUDEBA, 1963, pp. 77-111. Allí el sociólogo norteamericano asocia esas tendencias a la situación social de los estratos bajos, particularmente en los países pobres con bajos niveles de instrucción, que predispone a sus miembros al maniqueísmo y al pensamiento estereotipado, las religiones intolerantes, la inseguridad económica, normas familiares rígidas, ausencia de un sentido del pasado y del futuro, anti-intelectualismo y, sobre todo, la exposición "al castigo, a la falta de amor, y a una atmósfera general de tensión y agresión desde su primera infancia” (pp. 100-101).

${ }^{39}$ Por cierto, hay más, como la psicología del conservadurismo de Glenn Wilson, posterior en algunos años, que relaciona el concepto, no con el espectro político, sino con un conjunto de actitudes (fundamentalismo religioso, defensa del orden establecido, punitivismo, militarismo, etnocentrismo, superstición y otras todavía, en su mayoría coincidentes con la personalidad autoritaria). Un resumen puede consultarse en el capítulo "Personalidad y política", por IBÁÑEZ, Elena, y ABREU, Yolanda, en SEOANE y RODRÍGUEZ, op. cit. nota $\mathrm{n}^{\circ} 23$, pp. 112 y 113 .

${ }^{40}$ EYSENCK, Hans Jürgen, Psicología de la decisión política, versión española de J. ROMERO MAURA, Barcelona: Ediciones Ariel, 1964, cfr. p. 180.

${ }^{41}$ Ídem, cfr. pp. 196 a 198. 


\section{Polít. crim. Vol. 14, No 27 (Julio 2019), Doc. 2, pp. 606-634 [http://politcrim.com/wp-content/uploads/2019/06/Vol14N27D2.pdf]}

presentes en muchas de las actitudes que configuran dicha mentalidad, si bien preponderan en fascistas y comunistas frente a los sujetos de un grupo neutro, son abiertas o desembozadas en el caso de los primeros, e indirectas y encubiertas en los segundos. ${ }^{42}$

Por su parte, Rokeach comenzó a elaborar hacia 1951 en la Universidad de Michigan una teoría sobre creencias apoyada en variables de psicología cognitiva. La investigación culminó en 1960 con una vasta descripción de dos clases de mentalidades, una abierta y otra cerrada (o dogmática). Ambas se organizan en torno de sistemas de creencias, sólo que la teoría se fija antes en la estructura de ellas que en sus contenidos, como con insistencia repite el autor, distinguiendo netamente esta pareja de aspectos. ${ }^{43}$ Como lo que cuenta es la estructura de las creencias, hallada la tipología estructural ésta podrá amoldarse a los más dispares contenidos ideológicos, autoritarios o liberales, democráticos o antidemocráticos. Un sistema de creencias representa el conjunto de creencias, expectativas e hipótesis, conscientes e inconscientes, que una persona asume en un momento determinado como verdaderas en el ambiente en que vive. Su opuesto es el descreimiento, todo aquello que el sujeto rechaza como falso. ${ }^{44}$ Creencias y no creencias son sistemas psicológicos, no otros de índole lógica, y admiten tres dimensiones, una según sus grados de diferenciación, otra que atiende a la centralidad o lugar periférico, al paso que la última considera la relación de ellas con el tiempo. ${ }^{45}$

Combinando estas dimensiones se obtiene dos sistemas de creencias, como se dijo, uno abierto y otro cerrado. El segundo se caracteriza por un alto nivel de rechazo de aquello en que el sujeto no cree, el aislamiento de las creencias entre sí, su acusada diferenciación respecto de las no creencias, una percepción del mundo como hostil, repugnancia o aceptación de las personas en función de su sistema de creencias, similar al propio o no, y una perspectiva limitada o estrecha del tiempo. ${ }^{46} \mathrm{La}$ mentalidad cerrada es también dogmática. La evidencia principalmente una actitud de defensa ante amenazas reales o presuntas del mundo circundante, en vez del despliegue de las funciones cognitivas que permiten a una mente abierta comprenderlo. La escala del dogmatismo que preparó Rokeach permitiría medir el grado de apertura o cerrazón de cualquier sistema de creencias, sea cual fuere su contenido ideológico. Ha suscitado críticas, aunque en parte vino a confirmar elementos de la escala $\mathrm{F}$ de la investigación de Berkeley. ${ }^{47}$

Las últimas indagaciones del autoritarismo en la psicología social se alejan aún más de la plataforma psicoanalítica de la teoría original, si bien coinciden parcialmente con sus resultados. La de Bob Altemeyer define el concepto como un conglomerado de actitudes determinadas por el aprendizaje social. Aunque el autor discurre de unas actitudes

\footnotetext{
42 Ídem, cfr. pp. 296 y 297.

${ }^{43}$ ROKEACH, Milton, The open and closed mind. Investigations into the nature of belief systems and personality systems, New York: Basic Books, Inc. Publishers, 1960, cfr. pp. 6 y 14, entre otras.

${ }^{44}$ Ídem, cfr. p. 33.

45 Ídem, cfr. pp. 35 a 53.

${ }^{46}$ Ídem, cfr. pp. 55 y 56.

${ }^{47}$ Por ejemplo, la importancia de la socialización infantil en la génesis del dogmatismo. El dogmático, al igual que el autoritario de Adorno, tiene un yo débil, es conformista, inflexible, rígido y con poca tolerancia a la frustración, como los niños. Cfr. SANGRADOR GARCÍA, en op. cit. nota n ${ }^{\circ} 24$, pp. 149 y 150, además del propio ROKEACH, op. cit. nota ${ }^{\circ} 43$, pp. 347-365 (capítulo Anxiety and childhood experience).
} 
autoritarias en lugar de la personalidad homónima, sus hallazgos confirman tres caracteres formulados por el grupo de Adorno como típicos del conglomerado actitudinal: sumisión autoritaria, agresión autoritaria y convencionalismo. Estos serían los signos de lo que llama «autoritarismo de derechas», aunque utilizando el calificativo, no en términos políticos, sino en otro psicológico-social. ${ }^{48}$ La escala con que medirlo, basada en una serie de experimentos realizados en Norteamérica y Europa, mostraría especialmente la hostilidad de la actitud autoritaria hacia las minorías raciales, sociales, políticas, religiosas y sexuales, tendencias agresivas que, sin embargo, con el mismo desenfado que las descarga contra el diverso, disculpan a las autoridades que cometen crímenes contra delincuentes comunes. ${ }^{49}$

En fin, John Duckitt enfoca los tres componentes actitudinales destacados por Altemeyer desde una perspectiva de identificación grupal, explicando el autoritarismo como un fenómeno de colectivos humanos, no de personalidades individuales. Con arreglo a la mayor o menor identificación del sujeto con el grupo de que forma parte, se tendría dos dimensiones opuestas. La primera consiste en la creencia de que las necesidades, inclinaciones y valores personales de los miembros del grupo deben subordinarse a la cohesión y los requerimientos de éste; la segunda, en cambio, indica que la cohesión grupal está subordinada en la mayor medida posible a la autonomía de sus miembros. ${ }^{50}$ Entonces, mientras más intensa sea la identificación del sujeto con su grupo, mayores serán su convencionalismo, sumisión u obediencia incondicionales a las autoridades e intolerancia y punitivismo contra las personas que no se ajusten a las normas y reglas del grupo de referencia. ${ }^{51}$ Estas proposiciones, que estarían empíricamente documentadas, confieren al autoritarismo un carácter netamente social, de reacción situacional "que puede manifestarse o expresarse sólo en el contexto de un grupo específico y la identificación grupal" 52 . En consecuencia, no es un fenómeno fijo o estable, tiene poca relevancia para la conducta individual, pero posee una "significación absolutamente fundamental para la comprensión de las diferencias individuales o de grupo en los fenómenos y conductas colectivos o intergrupales." 53

Concluyendo este acápite, agreguemos que el uso de la distinción de grupos endógenos y exógenos ratifica la vitalidad del estudio psicológico del autoritarismo en el momento

\footnotetext{
48 "Este autoritarismo - explica - es de derechas en el sentido de que se trata de una sumisión a las autoridades establecidas", y "su objetivo es preservar el orden establecido agrediendo a aquellos que lo desafían. Es posible que existan personas autoritarias de izquierdas que se someten a las autoridades revolucionarias dedicadas a derrocar violentamente el orden establecido". ALTEMEYER, Bob, "Nacionalismo y autoritarismo de derechas entre legisladores americanos", en la revista Psicología Política, número 7, 1993, p. (7-18) 8.

49 Los demás rasgos de la personalidad autoritaria apuntados por Adorno y Sanford los descarta ALTEMEYER por faltarles, a su entender, comprobación empírica y ser más bien productos de una teoría preconcebida, el psicoanálisis. Cfr. Right-Wing Authoritarianism, Winnipeg: University of Manitoba Press, 1981, pássim.

${ }^{50}$ DUCKITT, John, "Authoritarianism and group identification: A new view of an old construct", en Political Psychology, vol. 10, número 1, 1989, cfr. pp. 63-84, p. 71.

${ }^{51}$ DUCKITT, John, "Authoritarianism and group identification: A new view of an old construct", op. cit., nota ${ }^{\circ} 50$, cfr. p. 70.

${ }^{52}$ DUCKITT, John, "Authoritarianism and group identification: A new view of an old construct", op. cit. nota $\mathrm{n}^{\circ} 50$, pp. 79.

${ }^{53}$ DUCKITT, John, “Authoritarianism and group identification: A new view of an old construct", op. cit. nota $\mathrm{n}^{\circ} 50$, pp. 79 y 82.
} 
actual, con los desafíos que plantea la reviviscencia de movimientos o discursos neonazis, ultranacionalistas, xenófobos y otras muestras de intolerancia o agresividad entre los seres humanos. $^{54}$

\section{Mentalidad autoritaria, actitudes punitivas y pensamiento penal}

El precedente repaso del autoritarismo en la Psicología evidencia que no hay uniformidad de visiones sobre la naturaleza, el carácter y las causas del fenómeno. El concepto aparece alternativamente ligado a la personalidad, a la psicología cognitiva y, en parte o exclusivamente, a variables de tipo social. De hecho, tampoco está claro qué es determinante en la conducta autoritaria, si el trasfondo caracterológico o el desempeño del ambiente, las variables psicológicas actitudinales o la influencia de situaciones sociales percibidas como una amenaza (depresión económica, anomia, humillación nacional, aumento de la criminalidad aparente o del simple miedo al delito, etc.). ${ }^{55}$

En todo caso, del panorama delineado se desprende que la psicología del autoritarismo tiene que tomar en cuenta la relación entre individuo y sociedad, así sea por el hecho de que la obediencia a la autoridad integra los procesos de socialización. ${ }^{56}$ Ahora, del análisis psicológico de esa relación fluyen, como elementos invariables, la sumisión, las tendencias agresivas, la identificación con el propio grupo y un grado indiferenciación del yo. Estos elementos coinciden en buena medida con los rasgos del autoritarismo en la vida política, que ya recalcamos, el poder de dominación, las jerarquías rígidas, la desigualdad. Con la combinación del sexteto de componentes se puede caracterizar lo que denominamos mentalidad autoritaria, un modo de pensar o configuración ideológica formado en parte por condicionamientos del carácter, en parte por influencias permanentes u ocasionales del ambiente. Este tipo de mentalidad permite ilustrar las actitudes punitivas del profano, aunque también las inclinaciones fundamentales del pensamiento penal autoritario. Las primeras vienen definidas por un perfil emocional de raíz atávica. Las segundas, a su vez, responden a un sistema de creencias bajo el cual pulsa una refinada racionalización del impulso vindicativo, mejor dicho, del miedo del propio yo ante la amenaza de desorden generada por el quebrantamiento de las normas que rigen al grupo social.

Por más que se haya convertido en tónica del momento actual en los países occidentales, la exacerbación de las actitudes punitivas del público no formado en el Derecho dista de ser

\footnotetext{
${ }^{54}$ Para la situación en Europa, cfr. SANGRADOR GARCÍA, en op. cit. nota $n^{\circ} 24$, pp. 157 y 158 , y SABUCEDO CAMESELLE, op. cit. nota $\mathrm{n}^{\circ} 14$, pp. 55 y 56; en el continente iberoamericano, ETCHEZAHAR, Edgardo, y BRUSSINO, Silvana, "Perspectivas psicológicas en el estudio del autoritarismo", en el volumen editado por MAGAÑA, Irene, DORNA, Alexandre, y TORRES, Iván, Contribuciones a la psicología política en América Latina. Contextos y escenarios actuales, Santiago de Chile: RIL Editores, 2016, pp. (85-105) 98 y 99.

${ }^{55}$ Cfr. SANGRADOR GARCÍA, en op. cit. nota n ${ }^{\circ} 24$, p. 159. Del mismo modo que, al revés, la psicología social no puede desconocer la experiencia instintiva, de la que importan aquí especialmente los impulsos de conservación propia, uno de los cuales es la venganza. Cfr. FLETCHER, Ronald, El instinto en el hombre. A la luz de las últimas investigaciones en psicología comparada, versión castellana de SALTZMAN, Carlos Eduardo, Buenos Aires: Editorial Paidós, 1962, pp. 324 y 325.

${ }^{56}$ Cfr. LHULLIER, Louise A., "Autoritarismo, autoridad y conciencia moral. Un análisis psico-social”, en la revista Psicología Política, número 11, 1995, p. 69-84, 70.
} 
un fenómeno reciente. ${ }^{57}$ Están enfeudadas en el humus del autoritarismo, a saber, la indiferenciación del yo, un hecho certificado por la Antropología y la Historia del Derecho penal. Si se busca algunas líneas generales en la trayectoria de esta rama del ordenamiento jurídico, lo único que se obtendrá es la constancia de dos tendencias, una que exalta al grupo como entidad substantiva y superior a sus miembros, otra que considera al individuo como sujeto de una finalidad propia y mira a la sociedad como un medio con que preservarle y proporcionarle las condiciones necesarias para el desarrollo de su personalidad. La lucha cultural en que va emergiendo el hombre como persona no es progresiva o ascendente, sino que oscila siempre entre estos dos polos. La primera tendencia, que es también la más antigua y rebelde, es sinónima de primitivismo en las cuestiones penales. Repárese, empero, en que esta calificación es antes cultural que histórica. Primitivismo significa escaso adelanto cultural, cuya falta es suplida por ciertas estructuras psíquicas, que son el desconocimiento de la causalidad y, en lo que nos interesa aquí, una menguada conciencia del yo, debido a lo cual el individuo forma y se siente un todo indiferenciado con los demás miembros de su familia, tribu o grupo. Así se explica que en el mundo antiguo no hubiese realmente homicidio en la muerte perpetrada contra sujetos ajenos a la colectividad de pertenencia del hechor y que la reacción vindicativa a las infracciones más graves tuviera a un agente y paciente grupales. ${ }^{58}$ La base atávico-afectiva del punitivismo debe tenerse presente a la hora de tasar otros elementos que se sabe influyen en su incremento actual, con lo que nos referimos al miedo al delito, la manipulación sensacionalista del crimen en los medios de comunicación social, la violencia policial, el endurecimiento de las penalidades y la agravación de las penas impuestas por los tribunales de justicia. ${ }^{59}$ Por encima de todo ello se yergue la identificación grupal y la

\footnotetext{
${ }^{57}$ Se trata de un asunto muy estudiado en algunos Estados, pero carente de investigación empírica en los países subdesarrollados, lo que, sumado a problemas metodológicos, explica la dificultad de efectuar análisis comparativos del punitivismo en general. El propio concepto no presenta la claridad que sería de desear, alberga varios niveles y, por la carga moral que entraña la palabra, algunos criminólogos recomiendan reemplazarla por la de firmeza frente al delito. Cfr. KURY, Helmut, y SHEA, Evelyn, Introduction, en ídem (editores), Punitivity. International developments, vol. II: Insecurity and punitiveness, Bochum: Universitätsverlag Dr. Brockmeyer, 2011, pp. (9-28) 9 y 16, y SERRANO MAÍlLO, Alfonso, y SERRANO GÓMEZ, Alfonso, "El aumento de la firmeza en la respuesta al delito a nivel legislativo en España (19952007)", en KURY, Helmut, y SERRANO MAÍlLO, Alfonso (editores), Punitividad y victimización en la experiencia contemporánea. Estudios, Madrid: Dykinson, 2009, pp. (294-316) 294-314.

${ }^{58}$ Cfr. MANZINI, Vicente, Paleontología criminal, Trad. revisada por C. BERNALDO DE QUIRÓS, Madrid: Casa Editorial Viuda de Rodríguez Serra, s/f., pp. 36 a 38; DURKHEIM, Emilio, Lecciones de Sociología. Física de las costumbres y del Derecho, versión directa del francés de MALDAVSKY, David, Buenos Aires: Editorial Schapire, 1966, pp. 107 y 108; KELSEN, Hans, Sociedad y naturaleza. Una investigación sociológica, Trad. PERRIAUX, Jaime, Buenos Aires: Editorial Depalma, 1945, pp. 15, 16, 24 y 29, y REDFIELD, Robert, El mundo primitivo y sus transformaciones, Trad. de GONZÁLEZ ARAMBURO, Francisco, México: Fondo de Cultura Económica, 1963, pp. 22 y 75.

${ }^{59}$ Temas profundizados y convenientemente separados por la Criminología y Política criminal. Véanse, entre otros, DÍEZ RIPOLLÉS, José Luis, La racionalidad de las leyes penales. Práctica y teoría, Madrid: Editorial Trotta, 2003, pp. 24-25; GARLAND, David, A cultura do controle. Crime e ordem social na sociedade contemporânea, Trad., presentación y notas NASCIMENTO, André, Río de Janeiro: Editora Revan, 2008, pp. 53-57, 338 y 386; REDONDO ILLESCAS, Santiago, "La delincuencia y su control: realidades y fantasías", en la Revista de Derecho penal y Criminología, de Madrid, $2^{a}$ Época, número 8, 2001, p. (309-325) 319; SCHEERER, Sebastian, "El círculo de reforzamiento político-periodístico. Sobre la influencia de los medios de comunicación en el proceso de gestación de la normativa penal", en la Revista de Derecho penal y

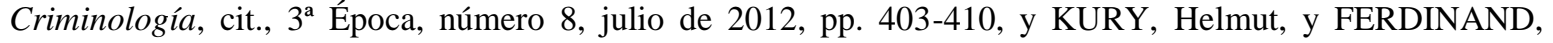
Theodore, "Miedo al delito, tamaño de la población, salidas a la calle y actitudes hacia la policía. Resultados
} 


\section{Polít. crim. Vol. 14, No 27 (Julio 2019), Doc. 2, pp. 606-634 [http://politcrim.com/wp-content/uploads/2019/06/Vol14N27D2.pdf]}

exclusión del delincuente o sospechoso de serlo del propio grupo, como si sus propiedades individuales, diferentes de las nuestras, lo tornasen un extraño y, en definitiva, un potencial enemigo. ${ }^{60}$

La mentalidad autoritaria queda retratada en un esquema básico de actitudes punitivas, en sí mismas independientes del contexto social, aunque pueden y de hecho son estimuladas por condiciones generales de la sociedad, particularmente el sentimiento de inseguridad que corroe a los países del primer mundo ${ }^{61}$, lo mismo que a Estados de subdesarrollo económico-social y acendrado autoritarismo. ${ }^{62}$

El primer grupo de actitudes, a nuestro juicio el más importante, desciende inmediatamente de la indiferenciación del yo individual y la identificación del sujeto con un yo colectivo. Se trata del apoyo incondicional y acrítico del sistema penal, de suerte que éste opere con eficiencia, sin importar si respeta o no los derechos de las personas, que detenga y castigue legal o ilegalmente. ${ }^{63}$ Estudios cuantitativos realizados en los Estados Unidos de Norteamérica indican la simpatía de las personas más pobres y de ilustración rudimentaria con la violencia policial y las condenas implacables, en el doble sentido de duras y no condescendientes con «tecnicismos legales» (en otras palabras, las garantías penales y procesales del Estado de Derecho). Este grupo actitudinal esconde el grueso de los componentes agresivos y jerárquicos del autoritarismo. Va de suyo que la identificación con el Estado que castiga opera con respecto de las personas marginadas o pertenecientes a minorías. $^{64}$

alemanes", Revista de Derecho penal y Criminología, cit., 2a Época, número 3, 1999, pp. 209-292. La paradoja del miedo al delito, destacada por los últimos dos criminólogos (cfr. pp. 226 y ss.), o sea, que ese sentimiento crece entre las personas menos expuestas a la victimización (mujeres y ancianos), adquiere explicación lógica a la luz de la indiferenciación del yo.

${ }^{60}$ Cfr. GARLAND, op. cit. nota $n^{\circ} 58$, p. 386. El fenómeno descansa en la agresividad y también, curiosamente, en una conciencia social poco desarrollada, conciencia que en modo alguno equivale a la identificación grupal, sino todo lo contrario. Desde el punto de vista psicoanalítico, véanse RIVACOBA Y RIVACOBA, Elementos de Criminología, cit. nota n ${ }^{\circ}$ 2, pp. 201 y 202, y FARRALL, Stephen, JACKSON, Jonathan, y GRAY, Emily, "La trascendencia cultural y social de la inseguridad ante la delincuencia", en el volumen editado por SERRANO MAÍLLO, Alfonso, y GUZMÁN DALBORA, José Luis, Procesos de infracción de normas y de reacción a la infracción de normas: dos tradiciones criminológicas. Nuevos estudios en homenaje al profesor Alfonso Serrano Gómez, Madrid: Dykinson, 2008, pp. 233-276, pp. 258259, en las que se explica cómo la delincuencia se ha transformado en un óptimo cauce en el cual el hombre contemporáneo puede proyectar y combatir su angustia e inseguridad en el «otro» delincuente, mejor que en cualquier individuo diverso de él.

${ }^{61}$ Cfr. KURY, Helmut, y OBERGFELL-FUCHS, Joachim, Punitiveness - Impact and measurements, en Punitivity. International developments, cit. nota $\mathrm{n}^{\circ}$ 56, pp. 165-206, p. 167.

${ }^{62}$ Cuyo es el caso de Chile, donde el tono autoritario impregna de antiguo la vida pública. Véase, con matices, SALINAS MUÑOZ, Claudio, "Aproximaciones a la noción de autoritarismo. Discusiones disciplinarias y la irrupción de la reflexividad comunicativa", Documentos de Trabajo, Santiago de Chile: publicación digital del Centro de Estudios de la Comunicación de la Universidad de Chile, número 6, otoño de 2009, pp. (5-30) 19-21.

${ }^{63}$ Vicente GARRIDO GENOVÉS, Vicente, Relación entre la sociedad y el sistema legal, en el volumen Psicología social y sistema penal, compilado por JIMÉNEZ BURILLO, Florencio, y CLEMENTE, Miguel, Madrid: Alianza, 1986, cfr. pp. 45-60, p. 52.

${ }^{64} \mathrm{Si}$ bien la actitud excluyente es compleja e imprecisa, amén de volátil, algo que sabe ser aprovechado, en el nivel político, por el llamado populismo punitivo, que no es otra cosa que la vieja demagogia denostada por los filósofos griegos de la época clásica. Cfr. KUNZ, Karl-Ludwig, Zum Konzept der «Punitivität» und seiner 
El segundo grupo acentúa todavía más los ingredientes emocionales, bajo los que quedan aplastadas las cogniciones elementales y distorsionadas de la mentalidad autoritaria sobre el problema penal. Esta mentalidad es reacia a aceptar algo así como un derecho de castigar, vertebrado en una relación jurídica y, por tanto, limitado o finito. Del mismo modo que en la teoría política el autoritarismo deposita sus esperanzas en la conservación y el robustecimiento del poder, así también la mentalidad autoritaria del profano padece del hechizo de la violencia, institucionalizada o no, en una doble y pretensa función de vindicar las fechorías y precaver su ocurrencia. Ni por un momento considera que la violencia genera más violencia o que las penas desproporcionadas tampoco sirven para el efecto de prevenir los delitos. ${ }^{65}$ Es más, rehusará participar en una discusión racional sobre estos argumentos, porque la inspira la certeza irreflexiva de que las cosas no pueden ser manejadas de otra manera que con la sumisión del irredento. Todo lo demás pertenece a la sofistería de autoproclamados especialistas, personas que han consagrado su vida al estudio del problema penal, pero a las que la mentalidad autoritaria combate como alimañas. La misma intuición de que nacen estas certidumbres inconmovibles le permite secundar que las leyes penales más severas sean aplicadas hacia atrás en el tiempo y, al revés, exigir que los delitos y penas no prescriban jamás.

En el tercer grupo de actitudes predomina la pobreza cognitiva de esta forma mentis. Para el autoritario no hay una diferencia cualitativa entre inmoralidad y antijuridicidad, por una parte, ni una graduación cuantitativa entre antijuridicidad y delito, por otra. Es típico de la mentalidad primitiva formar un todo indiferenciado con los diversos ordenamientos reguladores de la conducta, al paso que el proceso de disgregación, indispensable para distinguir el Derecho de la moral y las costumbres sociales, la propia posibilidad de que el comportamiento antisocial adopte diferentes formas, es producto del desenvolvimiento de la cultura y del afinamiento de la razón en los sujetos. ${ }^{66}$ De ahí que estas personas se sentirán conformes con la sanción como delito de conductas que no ofenden a otros, pero que demuestran desobediencia a los mandatos del superior, celebrarán el castigo con pena de actos sólo indecorosos o reprobables desde el punto de vista de la ética social y que reclamen penas duras para todos los culpables de delito, desde los más triviales a los más serios. ${ }^{67}$ En el fondo, estamos ante una nueva experiencia de la degradación del ius puniendi a mero poder penal.

Entwicklung im Internationalen Vergleich, en BOERS, Klaus, FELTES, Thomas, KINZIG, Jörg, SHERMAN, Lawrence W., STRENG, Franz, y TRÜG, Gerson (editores), Kriminologie - Kriminalpolitik Strafrecht. Festschrift für Hans-Jürgen Kerner zum 70. Geburtstag, Tübingen: Mohr Siebeck, 2013, p. (113126) 113.

${ }^{65}$ Helmut KURY y Joachim OBERGFELL-FUCHS, en op. cit. nota n56, cfr. pp. 185-190.

${ }^{66}$ Cfr. MAYER, Filosofía del Derecho, cit. nota n ${ }^{\circ} 12$, p. 96.

${ }^{67}$ Cfr. SANGRADOR GARCÍA, en op. cit. nota ${ }^{\circ}$ 24, pág. 142, y KURY, Helmut, y OBERGFELLFUCHS, Joachim, en op. cit. nota $\mathrm{n}^{\circ}$ 56, pp. 180-181 (a propósito del punitivismo de los jueces, que es ya otro nivel del problema). Es verdad que una información honesta y equilibrada sobre la criminalidad ayuda a reducir el miedo al delito, pero la prepotencia de los componentes emocionales en la actitud punitiva nos hacen recelar de que esa información pueda por sí sola contrarrestarla. Véanse, en todo caso, KURY, Helmut, OBERGFELL-FUCHS, Joachim, y FERDINAND, Theodor N., "Desarrollo de la sociedad y evolución de la delincuencia: una comparación internacional", Trad. del inglés de SERRANO MAÍLLO, Alfonso, en la Revista de Derecho penal y Criminología, cit., $2^{a}$ Época, n 6, 2000, pp. (307-404) 360-361. 


\section{Polít. crim. Vol. 14, No 27 (Julio 2019), Doc. 2, pp. 606-634 [http://politcrim.com/wp-content/uploads/2019/06/Vol14N27D2.pdf]}

Como contrapartida, existe un último grupo general de actitudes punitivas que recuperan para el sujeto su agresividad latente, normalmente proyectada y sublimada en la figura del grupo protector. Es la condescendencia en la autotutela. La mentalidad punitiva bendice las defensas privilegiadas, así sea que la reacción defensiva acabe en la muerte del agresor, festeja la detención por particulares y ojalá también el tormento inmediato de delincuentes flagrantes, apoya el ejercicio arbitrario de derechos propios o facultades sólo presuntas del sujeto actuante, como dañar bienes del que nos injurió o perturbó de alguna manera, apoderarse de cosas del deudor renitente, vengar sin escrúpulos las ofensas, tomando para todo ello como modelo la «viril» estampa del mafioso, acaso regocijándose en la ensoñación de ser alguna vez un padrino.

Anticipamos que las inclinaciones fundamentales del pensamiento penal autoritario pueden ser reconducidas al concepto psicológico de creencia. En el caso del jurista, precisamente por su formación especializada, tal concepto resulta más apropiado que las simples actitudes. Dijimos, además, que se trataría de un sistema de creencias bajo el que late una racionalización del impulso vindicativo. Como se sabe, la venganza, indiscutida fuente primigenia de la pena, no es sino el mismo instinto de conservación exagerado por el peligro. La verdadera función de su vástago, según la perspectiva sociológica de Durkheim, es mantener intacta la cohesión social, "expresar la aversión unánime que el crimen continúa inspirando, por medio de un acto auténtico, que sólo puede consistir en un dolor que se inflige al agente". ${ }^{68}$ El designio larvado, a menudo inconsciente, de controlar mediante la pena las emociones que el delito sublevó, asegurar los sentimientos colectivos en que descansa la cohesión social, opera con la espontaneidad automática típica de las comunidades menos adelantadas, en las que gobierna una solidaridad asimismo mecánica que se contenta con la tosca semejanza de un mal que reobraría sobre otro mal. Pues bien, el progreso social hace mella en el deseo de venganza, en la rebelión de la dignidad colectiva $^{69}$, espiritualizándolo de varias maneras, siendo la preferida la especulación sobre el fin de la pena, unas teorías desde las cuales puede el criminalista levantar, con relativa tranquilidad, el edificio del pensamiento penal sistemático. Sin embargo, hay un punto de artificio, un indicio de ascendencias inconscientes en esta racionalización. El pensamiento penal que llamaremos genéricamente autoritario no se hace realmente cargo del problema del fundamento del derecho de castigar, que va antepuesto a la cuestión del sentido de la pena. Muy por el contrario, lo escamotea so pretexto de justificaciones idealistas de dudosa corrección lógica. ${ }^{70}$ No advierte o no querría apercibirse de que dicho fundamento,

\footnotetext{
${ }^{68}$ DURKHEIM, Émile, La división del trabajo social, Trad. Carlos G. Posada, México: Colofón, 6a ed., 2016, cfr. pp. 97 y 118.

69 RUIZ FUNES, Mariano, Actualidad de la venganza. (Tres ensayos de Criminología), Buenos Aires: Editorial Losada, S.A., 1944, cfr. p. 36.

${ }^{70}$ La mayoría de las teorías que brindan una respuesta afirmativa a este crucial asunto — y casi todas dan una decididamente afirmativa-, no pasan de ser juicios analíticos, vacuas abstracciones, cuando no simples tautologías. Cuando se dice, por ejemplo, que el Derecho penal existe en la vida humana como un medio imprescindible para salvaguardar las condiciones de subsistencia de la comunidad, nada se añade a un elemento contenido en el concepto de Derecho, que regula bilateralmente la conducta y presupone la existencia de una comunidad. Si, en cambio, se afirma que su fundamento es la dignidad del hombre y la exigencia de preservar derechos básicos de éste, tampoco añadimos algo nuevo al concepto, que continúa suspendido en una atmósfera ideal y huérfano de justificación. Algo parecido cabe replicar a quienes alegan que dicho fundamento yace en la necesidad de proteger a la sociedad a través de la salvaguarda de sus bienes jurídicos más importantes, porque en el concepto de Derecho está enclavada la orientación de sus
} 
suponiendo que exista, hay que buscarlo por encima o por debajo del concepto de Derecho penal. Dado que la primera alternativa, la justificación desde arriba, perdió consistencia con el derrumbe del Estado absoluto y ya nadie sostiene en serio que un principio divino o ético justifique la existencia del derecho de castigar, el hecho es que los criminalistas debimos de perder irremediablemente la buena conciencia a la hora de castigar. ${ }^{71}$ Sólo queda franco un fundamento real al problema propuesto, a saber, la necesidad de precaver mediante la previsión de los delitos y la imposición de las penas la venganza, cuya ilimitación amenazaría con aniquilar la base misma de la existencia social, el hombre. ${ }^{72}$

Pero mientras el pensamiento penal antiautoritario conserva siempre la mala conciencia, por lo que no cederá al componente expiatorio de la punición y procurará solamente que ésta contenga en lo posible las represalias a que daría lugar la impunidad del delito, su homónimo autoritario dará por bueno el trasfondo irracional del ímpetu expiatorio, conveniente disimulado en una ideología naturalista o normativista. ${ }^{73}$ De semejantes ideologías proviene la idea de que "todo Derecho penal es autoritario so pena de suicidio". "En verdad, el Derecho penal descansa en el concepto de autoridad, que sabemos no tiene nada que ver con el autoritarismo. ${ }^{75}$ La autoridad penal debe su razón de ser a relaciones jurídicas; el autoritarismo punitivo se apoya simplemente en el poder.

Ahora, con pensamiento penal autoritario no entendemos referirnos en esta sede a las corrientes de pensamiento confesadamente iliberales y antidemocráticas, de esas que medraron al socaire del totalitarismo, como la escuela de Kiel, el materialismo penal

prescripciones hacia fines valorados. La exacerbación de la circularidad aparece en la teoría según la cual el Derecho hallaría su justificación en la idea pura de voluntad o libertad autoconsciente. Sobre todo ello nos pronunciamos en nuestro libro Elementi di Filosofia giuridico-penale, cit. nota ${ }^{\circ} 1$, pp. 82 y ss.

${ }^{71}$ RADBRUCH, Gustav, Introduzione alla scienza del diritto, Trad. di PASINI, Dino, e AGNESOTTI, Carlo A., Torino: Giappichelli, 1961, cfr. p. 224. Semejante en su defensa del Derecho penal antiautoritario, últimamente, VORMBAUM, Thomas, Saggi di storia del Diritto penale moderno, Napoli: Edizioni Scientifiche Italiane, 2018, capítulo 9 («Diritto penale antiautoritario»), especialmente pp. 132, 135 y 136.

${ }^{72}$ Por la Psicología profunda sabemos las funciones psíquicas que cumple la pena y las fuerzas también psicológicas sobre las que reobra. Los delitos despiertan sentimientos instintivos que, de no hallar una satisfacción simbólica a través de la pena, producirían reacciones espontáneas de represalia, individual o colectiva, pero siempre desproporcionada y brutal. La necesidad afectiva de reprimir los deseos íntimos, que todos llevamos adentro, de homologar la hazaña del delincuente y, a la vez, vengarnos del enemigo externo por haberse permitido el placer indebido de realizar sus propios deseos, en suma, el clamor del instinto de conservación exasperado por el peligro, hallan una canalización racionalizada en la pena. Aunque ésta nació para combatir la venganza, primero encauzándola mediante la sanción de los delitos privados, luego sublimándola en la pena pública, conserva todavía residuos vindicativos. Yendo más atrás, "la conexión profundamente radicada en el individuo entre culpa y expiación, nos constriñe a tomar posición frente a estos presupuestos irracionales del Derecho penal". ALEXANDER, Franz, y STAUB, Hugo, Il delinquente, il giudice e il pubblico. Un'analisi psicológica, prefazione di VELTRI, Pietro e traduzione di VELTRI, Pietro, y DE BERNARDI, Laura, Giuffrè, Milano, 1978, p. 185.

${ }^{73}$ Una consiste en asumir explicaciones empíricas como justificaciones axiológicas, la otra imagina que éstas expresarían una descripción de lo que sucede en la realidad. En todo caso, el defecto de estas construcciones ideológicas, verdaderas falacias, es circular, con lo que queremos decir que los fautores de una clase lo son también de la otra, aunque no perciban ninguna de las dos. Cfr. FERRAJOLI, Luigi, Il paradigma garantista. Filosofia e critica del Diritto penale, Napoli: Editoriale Scientifica, $2^{\mathrm{a}}$ ed., 2016, pp. 27-30.

${ }^{74}$ BETTIOL, Giuseppe, El problema penal, Trad. de GUZMÁN DALBORA, José Luis, y prólogo de RIVACOBA Y RIVACOBA, Manuel de, Buenos Aires: Hammurabi, 1995, p. 72.

${ }^{75}$ Recuérdese lo expresado supra, texto y nota $\mathrm{n}^{\circ} 11$. 


\section{Polít. crim. Vol. 14, Nº 27 (Julio 2019), Doc. 2, pp. 606-634 [http://politcrim.com/wp-content/uploads/2019/06/Vol14N27D2.pdf]}

soviético o los corifeos criminalistas del fascismo. Son ejemplos muy conocidos a los que nada tendríamos que agregar, salvo la indicación de que en ellos predominó la faceta política del autoritarismo, con su fe en el poder, la jerarquía y la desigualdad. ${ }^{76}$ Aquí nos interesa caracterizar en sus rasgos fundamentales el pensamiento penal no afiliado explícitamente a una orientación ideológico-política de armazón autoritaria, pero que refleja, lo quiera o no, una mentalidad afín. Es evidente que esta mentalidad le imprimirá características semejantes a las del autoritarismo declarado, comenzando por la desconfianza en la participación popular en el poder, que descansa en la igualdad de los seres humanos, al paso que "quien considera que los seres humanos son por naturaleza desiguales querría limitar esa creciente participación en el poder, conservando las instituciones así como son o restableciéndolas así como eran". 77 Con todo, lo medular en el pensamiento penal que nos preparamos a describir, mucho más extenso y difundido que el de organizaciones políticas autocráticas, no está en su inspiración política manifiesta, sino en los resortes psicológico-emocionales de la identificación con el grupo y la consiguiente indiferenciación del yo, ambos racionalizados bajo la persuasión de que el derecho de castigar es, finalmente, incuestionable y que las penas cumplen funciones sociales de las que la sociedad no puede ni debe prescindir.

Hablando en general, este pensamiento no acaba de conformarse con la legalidad de delitos y penas, que representa una limitación del poder punitivo; tampoco simpatiza con la igualdad de los justiciables ante la ley, porque su eje es la totalidad; recela de la disidencia y aprueba la consideración como delito de la expresión de pensamientos; cifra su foco de atención, no en un ataque objetivo a bienes jurídicos, sino en la disposición interna criminal, peligrosidad o simple rebeldía del inculpado; castigará con pena los actos preparatorios y equiparará la tentativa a la consumación; hará responder al hombre por su conducta o trayectoria vital, en lugar de por sus actos singulares, lo que es ostensible en la justificación doctrinal de la reincidencia; verá en el delincuente un ser inferior, desadaptado, un enemigo; en fin, recrudecerá, desproporcionará y, finalmente, deshumanizará las penas, imprimiéndoles un timbre defensista de la colectividad.

Más circunscritamente, el autoritarismo penal se nos descubre en la solución de problemas interpretativos y la formulación de algunos conceptos que jalonan la Parte general de nuestra disciplina. Vaya de ello una sinopsis enunciativa y deliberadamente incompleta.

En la teoría de las fuentes se estimará satisfecho el concepto de la única inmediata del Derecho penal también en el caso de las leyes en blanco y los decretos leyes, que otorgan al gobierno del Estado una voz determinante en la definición de delitos y penas. En seguida, se construirá unos y otras con elementos tomados del Derecho interno y otros del Derecho internacional, algo efectivamente acaecido en la jurisprudencia sobre persecución nacional

\footnotetext{
${ }^{76}$ Esto, empero, no implica en absoluto que las construcciones doctrinales no realizadas bajo regímenes de ese jaez carezcan de un trasfondo político. Todo sistema penal lo entraña, aunque no sea "manejado políticamente por ningún buró, consejo o soviet". ZAFFARONI, Eugenio Raúl, Doctrina penal nazi. La dogmática penal alemana entre 1933 y 1945, prólogo de MUÑOZ CONDE, Francisco, Buenos Aires: Ediar, 2017, p. 284.

77 Por donde "conservadurismo y autoritarismo son compañeros de ruta". LOSANO, Mario G., Sistema e struttura nel Diritto, 3 vols., Milano: Giuffrè, t. II (Il Novecento), 2002, p. 167.
} 
de crímenes internacionales. ${ }^{78} \mathrm{Se}$ formulará interpretaciones analógicas o admitirá derechamente la analogía, por ejemplo, asegurando que los dedos de la mano humana estarían incluidos en el concepto legal de objeto o que las cosas embargadas comprenden las que se entrega en depósito o prenda. Se reducirá la esfera de los concursos aparentes de leyes penales a favor de los concursos ideal o real de delitos, $v$. gr., con la opinión de que el detenido que se evade vistiendo ropa del servicio de prisiones comete hurto, además del hecho contra la Administración de Justicia del que lo extrajo de la cárcel, o que quien emplea un arma que detenta ilegalmente para perpetrar un robo, responde de éste y del porte ilegal del arma. Se favorecerá la expulsión administrativa de extranjeros, a expensas de las reglas y garantías de la extradición. Sobre todo, se aplicará retroactivamente leyes penales so capa de que la cuestión pertenece al proceso penal o al Derecho administrativo, como ha pasado tras la ampliación legal de plazos prescriptivos, la introducción de causas inéditas de suspensión del término, la extensión a posteriori del período mínimo de cumplimiento de la pena de prisión para acceder a la libertad condicional y las modificaciones perjudiciales para el preso en el régimen de faltas a la disciplina y salidas al medio libre.

Yendo a la teoría del delito, esta manera de pensar no trepida en calificar de crimen el terrorismo y los hechos de opinión que pudiesen conmover el orden público. Tampoco divisa problemas de legalidad en los delitos de comisión por omisión, acepta delitos sin resultado, cohonesta los de peligro presunto.$^{79}$ Especialmente significativa es la cuestión de la tipicidad. El autoritarismo penal es refractario al predominio del tipo sobre los restantes elementos del delito, una función rectora que asegura el imperio de la ley en cada uno de los intersticios del sistema y que confiere al nulla poena sine lege penale la importancia que merece en la metodología jurídica. ${ }^{80}$ Por ende, tenderá a disociar del tipo antijuridicidad, culpabilidad y accidentes del hecho punible, con lo cual no sólo se extravía la función de enlace de la tipicidad, sino que queda resquebrajada la organización en niveles de toda la estructura del delito. No verá inconvenientes en los tipos abiertos culposos, de comisión por omisión, sin conducta o con elementos normativos indeterminados, conceptos generales, etc.- y, antes bien, imprimirá a las categorías imprecisas la mayor extensión posible, incluso desvinculándolas del mandato jurídico, como se aprecia en las fuentes de garantía propuestas por la teoría material de la comisión por omisión y en la mengua de una tipificación explícita, cabalmente determinada, de variedades supuestamente culposas del hecho. En sede de antijuridicidad es elocuente del temple que comentamos su rechazo del consentimiento del titular respecto de preeminentes bienes jurídicos, como la vida y la salud, solución que debilita el principio de personalidad en las relaciones jurídicas y proclama la contradictoria idea de que la vida es del individuo, sí, pero en el más allá, porque la existencia biológica no es protegida por consideración a su

\footnotetext{
${ }^{78} \mathrm{Al}$ respecto, remitimos a GUZMAN DALBORA, José Luis, "El tratamiento de los crímenes internacionales en la jurisprudencia chilena: una cabeza de Jano", Lateinamerika Analysen. Institut für LateinamerikaStudien, Hamburg, año 18, n 3, 2007, pp. 95-122.

${ }^{79}$ Cfr. FERRAJOLI, Luigi, Diritto e ragione. Teoria del garantismo penale, Bari: Laterza, 1989, p, 77.

${ }^{80}$ Así, BELING, Ernst, "Il significato del principio: «nulla poena sine lege poenali» nella determinazione dei concetti fondamentali del Diritto penale", traducción de VITO, Ernesto, en la revista La giustizia penale, vol. XXXVII (VII de la 4ª Serie), Roma, 1931, cfr. pp. (319-329) 319.
} 
portador, sino en pro de la colectividad. ${ }^{81}$ En la imputabilidad y culpabilidad se manifiesta de nuevo la disminución de la férula del principio de legalidad y la ineficacia de su precipitado técnico, la tipicidad. Nuestra mentalidad se entretiene en alternativas para mantener en pie la teoría de las acciones libres en la causa; dilata el dolo, de modo de referirlo a las acciones y no a los resultados típicos; además, lo normativiza en lugar de asentarlo en sus bases psíquicas; desconfía de la relevancia del error de prohibición, descartándolo mediante nociones como la ceguera, indiferencia o ignorancia deliberada de las exigencias jurídicas, la incapacidad del justiciable de intuir los cambios de la jurisprudencia judicial o administrativa, etc.

El ciudadano sentirá el asedio de la ideología subyugadora que lo trata como un súbdito incluso en los accidentes del delito. Los ejemplos que se podría aducir son cuantiosos. La imputación subjetiva de las circunstancias agravantes, cuando su umbral mínimo se hace radicar en el desconocimiento evitable del supuesto de hecho; la improcedencia de atenuantes putativas $\mathrm{y}$, en cambio, la adhesión a atenuantes fundadas en la entrega de codelincuentes y la delación de terceros ${ }^{82}$; la distinción meramente especulativa, no legal, entre preparación y tentativa ${ }^{83}$; la punibilidad indiscriminada de la tentativa inidónea del particular, acompañada por la impunidad de la tentativa idónea de agentes de la policía en el papel de provocadores ${ }^{84}$; el deslinde no típico de autoría y participación; la comunicabilidad de elementos personales a los partícipes; la inclinación a divisar acciones múltiples allí donde su sentido denota sólo una, etc., etc.

En el sistema de penas la mentalidad autoritaria no sólo da por buenas puniciones desacreditadas, sino que defiende la extensión de su contenido jurídico. Las privativas de la libertad pueden abarcar muchos más derechos que la autonomía ambulatoria, como sostiene la todavía invicta doctrina de la relación especial de poder entre el Estado y el reo. Otro tanto se efectuará con las demás penas. Gusta la multa según el sistema de suma global y, de prever la ley uno menos desigual con que graduarla, se hará lo posible para que el cálculo de las fuerzas patrimoniales la torne al condenado muy penosa de solventar. El comiso será interpretado de modo que su objeto material comprenda no sólo los instrumentos efectivamente utilizados en la comisión del delito y su producto, sino también

\footnotetext{
81 Acerca del valor político-jurídico de la disponibilidad de la propia vida, véase RIVACOBA Y RIVACOBA, Manuel de, "Nuevo sentido de la protección penal de la vida humana", en la Revista de Derecho, Consejo de Defensa del Estado, Santiago de Chile, año 1, n 3, abril de 2001, pp. 115-127, y del significado autoritario de las posturas que le niegan toda eficacia desincriminante, ZAFFARONI, Eugenio Raúl, Derecho penal. Parte general, con la colaboración de ALAGIA, Alejandro, y SLOKAR, Alejandro, Buenos Aires: Ediar, 2a ed., 2002, p. 499.

${ }^{82}$ Véase GUZMAN DALBORA, José Luis, "Del premio de la felonía en la Historia jurídica y el Derecho

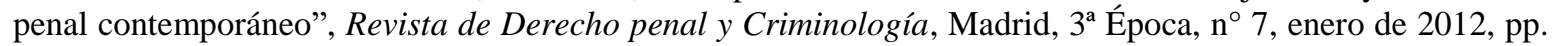
175-196.

${ }^{83}$ Es impropio hablar de una interpretación en las explicaciones o comprensiones especulativas de la vida o del mundo, "porque el curso y los resultados de la interpretación propiamente dicha son controlables en su exactitud, según la observancia de ciertos cánones hermenéuticos; la explicación especulativa, no: ella permanece abandonada al instituto y a la coherencia del sistema escogido". BETTI, Emilio, Interpretação da lei e dos atos jurídicos. Teoría geral e dogmática, Trad. portuguesa de JANNINI, Karina. São Paulo: Martin Fontes, 2007, p. XLII.

${ }^{4}$ GUZMÁN DALBORA, José Luis, "El delito experimental”, en la Revista de Derecho penal y Criminología, cit., $2^{\mathrm{a}}$ época, $\mathrm{n}^{\circ} 19$, enero de 2007, pp. 289-308.
} 
los instrumentos destinados al delito doloso y los «instrumentos» del culposo, los frutos, ganancias y bienes que substituyeron el producto del delito, su objeto material, etc., en una espiral decididamente confiscatoria. Las penas restrictivas de la libertad irán acompañadas de mecanismos físicos de señalamiento infamante. Las de interdicción incluirán la infamia a través de listas públicas de condenados. ${ }^{85}$ Naturalmente, se aprobará el aumento de las temporales y la proliferación de las perpetuas.

En fin, la caricatura del ius puniendi vuelve a asomar su burda indumentaria en la inteligencia doctrinal y aplicación jurisprudencial de las causas que extinguen la responsabilidad penal. La muerte del condenado no elimina todas las consecuencias penales del hecho, pudiendo sufrirlas también otros individuos, dado que esta mentalidad no es amiga de la personalidad de las penas y, al contrario, se recrea en la responsabilidad familiar o grupal. El perdón del ofendido es considerado inadmisible en los delitos dependientes de instancia particular, se lo critica en los de acción privada y, en general, queda bajo sospecha en todos los que ofenden a personas individuales, por lo cual también el efecto extintivo de la reparación del daño tropezará con reparos fundados en el principio de comunidad. La rehabilitación del penado no opera ipso iure, con el solo cumplimiento de la condena, y habrá delitos o penas que, a juicio de este temperamento, no son merecedores de la garantía de la prescripción.

Podríamos extendernos sobre un florilegio de delitos y descubriríamos con facilidad la huella del autoritarismo en su reconstrucción dogmática, partiendo por la cuestión del bien jurídico ofendido y el carácter de la ofensa, pasando por el abanico de los elementos típicos, la admisibilidad de eximentes, etc., hasta llegar a las puniciones, que se acumulará con desenvoltura a las de otros en supuesto concurso. Sin embargo, no parece necesario descender a los detalles. La idea general que preside el manejo autoritario de la Parte especial consiste en blindar interpretativamente los intereses del grupo al que pertenece el exégeta, sobre todo los de quienes le están por encima en la estructura social o de poder, y desentenderse de las pretensiones de los grupos inferiores. Este temple coincide con lo que en Italia llaman «Derecho penal del privilegio» ${ }^{86}$, las prácticas penales de la desigualdad.

\section{Balance}

Formada como una estructura psicológica en la que se reúnen componentes instintivos y elementos incorporados durante la configuración de la personalidad, la mentalidad autoritaria es especialmente propensa a la drasticidad en las ideas sociales y el pensamiento político. Es más, armoniza a la perfección con ellos, como si el trasfondo íntimo y la proyección exterior del autoritarismo fuesen dos vectores de un mismo agente. La combinación de tales facetas, su origen psíquico y desenlace colectivo, trae como resultado la conversión de la violencia psicológica en dureza política, la mudanza del sujeto fundido con el grupo en tirantez jerárquica en las relaciones con otros y, por último, una simbiosis de la angustia ingénita a la indiferenciación del yo con el trato desigual a los demás. Así se

\footnotetext{
${ }^{85}$ Nos explayamos sobre estas y otras manifestaciones del autoritarismo en el sistema de penas en nuestro libro La pena y la extinción de la responsabilidad penal, Santiago de Chile: LegalPublishing, 2008, pp. 184190, 225-226, 256, 267-269 y 289.

${ }^{86}$ MANTOVANI, Ferrando, Diritto penale. Parte generale, Padova: Cedam, $4^{\mathrm{a}}$ ed., 2001, cfr. p. XXIX.
} 


\section{Polít. crim. Vol. 14, No 27 (Julio 2019), Doc. 2, pp. 606-634 [http://politcrim.com/wp-content/uploads/2019/06/Vol14N27D2.pdf]}

llega al trastrueque que provoca invariablemente el autoritarismo en la relación entre humanidad y hombre.

Pudiéramos entonces dejar en sordina la significación de la mentalidad autoritaria en las actitudes punitivas y el pensamiento penal, pese a que fue objeto precipuo de estas páginas. En verdad, que semejante organización espiritual condicione decisivamente aquellas actitudes y modele deliberada o impremeditadamente este pensamiento, era una consecuencia previsible, incluso obvia, por lo que bien pudiese el lector interrogarse acerca de la necesidad entretenerse estudiándola. Como sea, es una constatación de importancia ínfima si se la compara con el sello radical, tajante e impiedoso que el autoritarismo imprime a todas las relaciones intersubjetivas y, en particular, la organización política de la comunidad.

Si nos detuvimos en el examen de su traducción penal fue por dos razones. Las personas reflexivas precisan adquirir conciencia del espectro psicológico que se esconde tras la inflexibilidad del punitivismo, no importa si del profano o el especialista. Que para nosotros, los hombres y mujeres que cultivamos el Derecho, el fantasma quede velado tras racionalizaciones como las descritas, que pudiéramos sintetizar en la idea de que severidad penal no es sinónimo de autoritarismo, eso tampoco resta un ápice de poder impelente a la soterrada fuerza ni, sobre todo, exime a una mente honesta del deber moral de examinarse a fondo, revisando el supuesto fundamental de sus construcciones especulativas y posturas científicas. En el profano, en cambio, el asunto adquiere unas dimensiones gigantescas. Recuérdese la fuente instintiva de este ser fantasmal. Las actitudes punitivas son sumamente indiciarias del tono en que está afinada la vida política de una comunidad. De no mantenerse a raya, asomarán crecientemente su cerviz como la punta de un tremendo iceberg cuya base acabará por hundir los derechos de las personas y devastar la democracia, que descansa en la noción de igualdad.

La reflexión acerca de las condiciones que posibilitan cohonestar públicamente el crepúsculo de los derechos fundamentales y poner sin remilgos una lápida al respeto democrático, nos conduciría demasiado lejos. Acaso brinden una pista las líneas generales de la lucha cultural que se libra en torno del Derecho penal, con la pareja de tendencias que coliden en ella. ${ }^{87}$ Otra señal la proporciona la historia del arte. La difusión del tema de la muerte en las postrimerías del siglo XV y principios del siglo XVI, las Danzas macabras, el Ars moriendi, las visiones infernales de Jerónimo Bosco, el Apocalipsis de Durero, surgieron del ambiente de incertidumbre de la sazón, cuando no se podía saber qué crecería de las ruinas del mundo estático y jerarquizado del Medioevo. El hombre pareciera no poder salir airoso por sí solo de los momentos de incertidumbre, lo domina la neurosis en las épocas de transición. ${ }^{88}$ Acudirá entonces a la antiquísima farmacopea de la aleación con

\footnotetext{
${ }^{87}$ Cfr., supra, texto y notas números 56 y 57.

${ }^{88}$ WESTHEIM, Paul, La calavera, Trad. de FRENK, Mariana, México: Fondo de Cultura Económica, $3^{\mathrm{a}}$ ed., 1996, cfr. p. 61.

Sea dicho que la teoría de los sentimientos de inseguridad, una doctrina sociológica inteligentemente aplicada al problema de las actitudes punitivas por Alfonso Serrano Maíllo, brinda una confirmación de lo que acabamos de manifestar. Según el autor, los sentimientos de inseguridad son un factor predictor de las actitudes firmes o severas ante el delito, sin que ello, empero, presuponga ningún tipo concreto de personalidad en su portador. No obstante, en su estudio sobre el dinamismo autoritario, Karen Stenner explica
} 
el grupo, así sea al precio de desprenderse de lo distintivo y constitutivo en él, su individualidad. Si hay protesta violenta en las escuelas, se desgañitará exigiendo la expulsión de los escolares revoltosos. De imperar la criminalidad convencional en algún barrio de la metrópoli, secundará razias armadas como exterminio de la plaga. Si cree que bandidos le imposibilitan circular tranquilamente por las calles o permanecer imperturbable en el abrigo del hogar, no titubeará un instante en sumarse al desenfreno de castigos promovido por orondos personajes que conocen al dedillo o cuando menos tienen una intuición precisa de estos resortes irracionales de nuestro ser.

Contribuir a lidiarlos mediante el conocimiento y la información, animados de la fundada esperanza de que podemos ser más que un simple fragmento de agrupaciones amorfas, creemos que es tarea impostergable de toda generación viva.

que la intolerancia y las actitudes punitivas requieren una predisposición especial, caracterizada por la valoración personal de la uniformidad y una autoridad que la sustente, la que es activada cada vez que se presenta una amenaza normativa, el temor de que la integridad del orden moral está en peligro y la percepción de que el «nosotros» se está desintegrando. Sin esa predisposición individual, pues, la dinámica del autoritarismo no se desencadenará, por la mayor resistencia de la predisposición opuesta, la libertaria, a las amenazas morales. Cfr. SERRANO MAÍlLO, Alfonso, Firmeza frente al delito y comunidad en la modernidad reflexiva. La tesis extendida de los sentimientos de inseguridad como teoría del control social, prólogo por KURY, Helmut, Madrid: Dykinson, Madrid, 2017, pp. 148-180, 248 y pp. 449-487, STENNER, Karen, The Authoritarian Dynamic, New York: Cambridge University Press, 2005, pp. 14, 17, 20 y 25. 


\section{Bibliografía}

ADORNO, Theodor: Escritos sociológicos, II, primera Parte, edición de TIEDEMANN, Rolf, Trad. de GONZÁLEZ RUIZ, Agustín, Madrid: Ediciones Akal, 2009.

ADORNO, Theodor, FRENKEL-BRUNSWIK, Else, LEVINSON, Daniel J., y SANFORD, R. Nevitt: The Authoritarian Personality, New York: Harper \& Row, 1950.

AGAMBEN, Giorgio: Estado de excepción. Homo sacer, II, I, Trad. de COSTA, Flavia, y COSTA, Ivana, con introducción y entrevista de Flavia Costa, Buenos Aires: Adriana Hidalgo Editora, 2007.

ALEXANDER, Franz, y STAUB, Hugo: Il delinquente, il giudice e il pubblico. Un'analisi psicológica, prefazione di VELTRI, Pietro e traduzione di VELTRI, Pietro, y

DEBERNARDI, Laura, Giuffrè, Milano, 1978.

ALTEMEYER, Bob: "Nacionalismo y autoritarismo de derechas entre legisladores americanos", en la revista Psicología Política, número 7, 1993, pp. 7-18.

ALTEMEYER, Bob: Right-Wing Authoritarianism, Winnipeg: University of Manitoba Press, 1981.

ARENDT, Hanna: Los orígenes del totalitarismo, versión española de SOLANA, Guillermo, Madrid: $\quad$ Taurus, 1968.

BELING, Ernst: "Il significato del principio: «nulla poena sine lege poenali» nella determinazione dei concetti fondamentali del Diritto penale", traducción de VITO, Ernesto, en la revista La giustizia penale, vol. XXXVII (VII de la 4ª Serie), Roma, 1931, pp. 319-329.

BETTI, Emilio: Interpretação da lei e dos atos jurídicos. Teoría geral e dogmática, Trad. Portuguesa de JANNINI, Karina. São Paulo: Martin Fontes, 2007.

BETTIOL, Giuseppe: El problema penal, Trad. de GUZMÁN DALBORA, José Luis, y prólogo de RIVACOBA Y RIVACOBA, Manuel de, Buenos Aires: Hammurabi, 1995.

D'ADAMO, Orlando y GARCÍA BEAUDOUX, Virginia: "Actitudes y conducta (actitudes políticas)", en la obra colectiva coordinada por MORALES, J. Francisco, PÁEZ, Darío, KORNBLIT, Ala Lía, y ASÚN, Domingo, Psicología social, Buenos Aires: Prentice Hall Pearson Educación, 2002, pp. 287-307.

DÍEZ RIPOLLÉS, José Luis: La racionalidad de las leyes penales. Práctica y teoría, Madrid: Editorial Trotta, 2003.

DEUTSCH, Morton, y KRAUSS, Robert M.: Teorías en psicología social, versión castellana de ZEIGNER, Silvia, Barcelona: Editorial Paidós, 1980.

DUCKITT, John: "Authoritarianism and group identification: A new view of an old construct", en Political Psychology, vol. 10, número 1, 1989, p. 63-84.

DURKHEIM, Émile: La división del trabajo social, Trad. Carlos G. Posada, México: Colofón, $6^{\text {a }}$ ed., 2016.

DURKHEIM, Emilio: Lecciones de Sociología. Física de las costumbres y del Derecho, versión directa del francés de MALDAVSKY, David, Buenos Aires: Editorial Schapire, 1966.

DUVERGER, Maurice: Instituciones políticas y Derecho constitucional, Prólogo de LUCAS VERDÚ, Pablo, $5^{\text {a }}$ edición española, totalmente refundida, dirigida por Jorge Solé-Tura, Barcelona: Ediciones Ariel, Barcelona, 1970.

EBENSTEIN, William: Pensamiento político moderno, versión española de LÓPEZ, Dolores, y CERVERA, Vicente, bajo la dirección de TIERNO GALVÁN, Enrique, Madrid: Taurus Ediciones, 1961.

ETCHEZAHAR, Edgardo, y BRUSSINO, Silvana: "Perspectivas psicológicas en el estudio del autoritarismo", en el volumen editado por MAGAÑA, Irene, DORNA, Alexandre, y TORRES, Iván, Contribuciones a la psicología política en América Latina. Contextos y escenarios actuales, Santiago de Chile: RIL Editores, 2016, pp. 85-105.

EYSENCK, Hans Jürgen: Psicología de la decisión política, versión española de J. ROMERO MAURA, Barcelona: Ediciones Ariel, 1964. 
FARRALL, Stephen, JACKSON, Jonathan, y GRAY, Emily: "La trascendencia cultural y social de la inseguridad ante la delincuencia", en el volumen editado por SERRANO MAÍLLO, Alfonso, y GUZMÁN DALBORA, José Luis, Procesos de infracción de normas y de reacción a la infracción de normas: dos tradiciones criminológicas. Nuevos estudios en homenaje al profesor Alfonso Serrano Gómez, Madrid: Dykinson, 2008, pp. 233-276.

FERRAJOLI, Luigi: Diritto e ragione. Teoria del garantismo penale, Bari: Laterza, 1989.

FERRAJOLI, Luigi: Il paradigma garantista. Filosofia e critica del Diritto penale, Napoli: Editoriale $\quad$ Scientifica, $2^{\mathrm{a}}$ ed., 2016.

FERRAJOLI, Luigi, y ZOLO, Danilo: Democracia autoritaria y capitalismo maduro, prólogo de IBÁÑEZ, Perfecto Andrés, Barcelona: Colección El Viejo Topo, 1980.

FLETCHER, Ronald: El instinto en el hombre. A la luz de las últimas investigaciones en psicología comparada, versión castellana de SALTZMAN, Carlos Eduardo, Buenos Aires: Editorial Paidós, 1962.

FROMM, Erich: El miedo a la libertad, Trad. de GERMANI, Gino, Buenos Aires: Paidós, 1993.

FÜLLER, Anna: Kritischen Theorie und die Studien zur Authoritarian Personality, Norderstedt: Grin Verlag, 2005.

GARCÍA JURADO, Roberto: "La personalidad autoritaria y la cultura cívica: de Adorno a Almond y Verba", en la Revista Mexicana de Ciencias Políticas y Sociales, vol. XLIX, número 201, septiembre diciembre de 2007, pp. 13-30.

GARLAND, David: A cultura do controle. Crime e ordem social na sociedade contemporânea, Trad., presentación y notas de NASCIMENTO, André, Río de Janeiro: Editora Revan, 2008.

GARRIDO GENOVÉS, Vicente: Relación entre la sociedad y el sistema legal, en el volumen Psicología social y sistema penal, compilado por JIMÉNEZ BURILLO, Florencio, y CLEMENTE, Miguel, Madrid: Alianza, 1986, cfr. p. 45-60.

GURVITCH, Georges: en Tratado de Sociología, t. II, traducción de EGUIBAR, María C. revisada por DUJOVNE, León, Buenos Aires: Editorial Kapelusz, 1963.

GUZMÁN DALBORA, José Luis: "Del premio de la felonía en la Historia jurídica y el Derecho

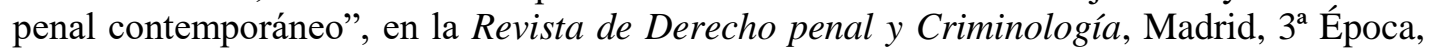
$\mathrm{n}^{\circ} \quad$ 7, enero de 2012, pp. 175-196.

GUZMÁN DALBORA, José Luis: Elementi di Filosofia giuridico-penale, a cura di Gabriele Fornasari y Alessandra Macillo, Napoli: Editoriale Scientifica, 2015.

GUZMÁN DALBORA, José Luis: "El delito experimental”, en la Revista de Derecho penal y Criminología, cit., $2^{a}$ época, ${ }^{\circ} 19$, enero de 2007, pp. 289-308.

GUZMÁN DALBORA, José Luis: "El tratamiento de los crímenes internacionales en la jurisprudencia chilena: una cabeza de Jano", en Lateinamerika Analysen. Institut für Lateinamerika-Studien, Hamburg, año 18, n 3, 2007, pp. 95-122.

GUZMÁN DALBORA, José Luis: La pena y la extinción de la responsabilidad penal, Santiago de Chile: LegalPublishing, 2008.

GUZMÁN DALBORA, José Luis: "Relaciones del Derecho penal con el Derecho constitucional, y su concreción en la Constitución política chilena (1980)", en el Anuario de Filosofía Jurídica y Social, publicación de la Sociedad Chilena de Filosofía jurídica y Social, Valparaíso: Edeval, n 12, 1994, pp. 165-199.

JIMÉNEZ DE ASÚA, Luis: Tratado de Derecho penal, publicados, 7 vols., Buenos Aires: Editorial Losada, $2^{a}$ ed., t. II, 1950.

KELSEN, Hans, Sociedad y naturaleza: Una investigación sociológica, traducción de PERRIAUX, Jaime, Buenos Aires: Editorial Depalma, 1945.

KERSHAW, Ian: Hitler, Trad. de FONTAL, Yolanda y SARDIÑA, Carlos, Barcelona: Ediciones Península, 2015. 
KRECH, David, CRUTCHFIELD, Richard S., y BALLACHEY, Egerton L.: Psicología social, Trad. del inglés de ÁLVAREZ VILLAR, Alfonso, Madrid: Biblioteca Nueva, $2^{\text {a }}$ ed., 1972.

KUNZ, Karl-Ludwig: Zum Konzept der «Punitivität» und seiner Entwicklung im Internationalen Vergleich, en BOERS, Klaus, FELTES, Thomas, KINZIG, Jörg, SHERMAN, Lawrence W., STRENG, Franz, y TRÜG, Gerson (editores), Kriminologie - Kriminalpolitik Strafrecht. $\quad$ Festschrift für Hans-Jürgen Kerner zum 70. Geburtstag, Tübingen: Mohr Siebeck, 2013, pp. 113-126.

KURY, Helmut, y SHEA, Evelyn: Introduction, en ídem (editores), Punitivity. International developments, vol. II: Insecurity and punitiveness, Bochum: Universitätsverlag Dr. Brockmeyer, 2011, pp. 9-28.

KURY, Helmut, y OBERGFELL-FUCHS, Joachim, Punitiveness - Impact and measurements, en Punitivity. International developments, cit., pp. 165-206.

KURY, Helmut, OBERGFELL-FUCHS, Joachim, y FERDINAND, Theodor N.: "Desarrollo de la sociedad y evolución de la delincuencia: una comparación internacional", Trad. del inglés de SERRANO MAÍlLO, Alfonso, en la Revista de Derecho penal y Criminología, de Madrid., $\quad 2^{\mathrm{a}}$ Época, $\mathrm{n}^{\circ}$ 6, 2000, pp. 307-404.

KURY, Helmut, y FERDINAND, Theodore: "Miedo al delito, tamaño de la población, salidas a la calle y actitudes hacia la policía. Resultados alemanes", en la Revista de Derecho penal y Criminología, de Madrid, $2^{a}$ Época, número 3, 1999, pp. 209-292.

LERSCH, Philipp, La estructura de la personalidad, con revisión y estudios preliminares de SARRÓ, Ramón y Trad. de SERRATE TORRENTE, A., Barcelona: Editorial Scientia, 1966.

LHULLIER, Louise A.: "Autoritarismo, autoridad y conciencia moral. Un análisis psico-social”, en la revista Psicología Política, número 11, 1995, p. 69-84.

LINTON, Ralph: Cultura y personalidad, Trad. de Javier Romero, México: Fondo de Cultura Económica, 1978.

LIPSET, Seymour Martin: El hombre político (1960), Trad. por MENDELEVICH, Elías, Buenos Aires: EUDEBA, 1963.

LÓPEZ, Mario Justo: Introducción a los estudios políticos, 2 vols., Buenos Aires: Ediciones Depalma, t. I, 1983.

LOSANO, Mario G.: Sistema e struttura nel Diritto, 3 vols., Milano: Giuffrè, t. II (Il Novecento), 2002.

MANTOVANI, Ferrando: Diritto penale. Parte generale, Padova: Cedam, $4^{\mathrm{a}}$ ed., 2001.

MANZINI, Vicente: Paleontología criminal, Trad. revisada por C. BERNALDO DE QUIRÓS, Madrid: Casa Editorial Viuda de Rodríguez Serra, s/f.

MAYER, Max Ernst: Filosofía del Derecho, Trad. de la $2^{\mathrm{a}}$ edición original por LEGAZ LACAMBRA, Luis, Barcelona: Editorial Labor, 1937.

MURGA FRASSINETTI, Antonio: "Teodoro Adorno y la personalidad autoritaria. Una lectura a 50 años de su publicación”, en la revista Argumentos, números 46-47, diciembre de 2003-abril de 2004, pp. 139-156.

ORTEGA Y GASSET, José: Ideas y creencias, Madrid: Espasa-Calpe, $8^{\text {a }}$ ed., 1976.

ORTIZ ZABALA, Milagros: Relaciones empíricas entre personalidad, autoritarismo y valores, Murcia: Secretariado de Publicaciones e Intercambio Científico, Universidad de Murcia, 1985.

OVEJERO BERNAL, Anastasio: "El autoritarismo: enfoque psicológico", en El Basilisco, número 13, noviembre de 1981-junio de 1982, pp. 40-44.

RADBRUCH, Gustav: Filosofía del Derecho, Trad. de MEDINA ECHEVARRÍA, José, Madrid: Editorial Revista de Derecho Privado, $3^{\mathrm{a}}$ ed., 1952.

RADBRUCH, Gustav: Introduzione alla scienza del diritto, Trad. di PASINI, Dino, e AGNESOTTI, Carlo A., Torino: Giappichelli, 1961. 
REDFIELD, Robert: El mundo primitivo y sus transformaciones, Trad. de GONZÁLEZ ARAMBURO, Francisco, México: Fondo de Cultura Económica, 1963.

REDONDO ILLESCAS, Santiago: "La delincuencia y su control: realidades y fantasías", en la Revista de Derecho penal y Criminología, de Madrid, 2a Época, número 8, 2001, pp. 309 325.

REICH, Wilhelm: Psicologia di massa del fascismo, Trad. di Furio Belfiore e Annelise Wolf, Milano:SugarCo Edizioni, 1982.

RIVACOBA Y RIVACOBA, Manuel de: Aproximación a Utopía, Santiago de Chile: Instituto de Chile, 1985.

RIVACOBA Y RIVACOBA, Manuel de: Elementos de Criminología, Valparaíso: Edeval, 1982.

RIVACOBA Y RIVACOBA, Manuel de: "Franco o el tirano. Ensayo de teoría política aplicada", en «Umbral», Revista mensual de arte, letras y estudios sociales, París, ${ }^{\circ} 29$, mayo de 1964 , pp. 4-6, continuado en $\mathrm{n}^{\circ} 30$, junio de 1964 , págs. $16-17$, y $\mathrm{n}^{\circ} 31-32$, julio y agosto de 1964, págs. 10-12.

RIVACOBA Y RIVACOBA, Manuel de: "Nuevo sentido de la protección penal de la vida humana", en la Revista de Derecho, Consejo de Defensa del Estado, Santiago de Chile, año 1, $\mathrm{n}^{\circ} 3$, abril de 2001, pp. 115-127.

RIVACOBA Y RIVACOBA, Manuel de: "Orden político y orden penal”, en la Revista Chilena de Derecho, Facultad de Derecho de la Pontificia Universidad Católica de Chile, vol. 22, $\mathrm{n}^{\circ} 2$ (monográfico: «Derecho penal y Criminología»), mayo-agosto de 1995, pp. 201-212.

ROKEACH, Milton: The open and closed mind. Investigations into the nature of belief systems and personality systems, New York: Basic Books, Inc. Publishers, 1960.

ROHRACHER, H.: Introducción a la caracterología, Trad.del alemán de LUZURIAGA, Lorenzo, Buenos Aires: Editorial Losada, $3^{\text {a }}$ ed., 1958.

RUIZ FUNES, Mariano: Actualidad de la venganza. (Tres ensayos de Criminología), Buenos Aires: Editorial Losada, S.A., 1944.

SABUCEDO CAMESELLE, José Manuel: Psicología política, Madrid: Editorial Síntesis, 2010.

SALINAS MUÑOZ, Claudio: "Aproximaciones a la noción de autoritarismo. Discusiones disciplinarias y la irrupción de la reflexividad comunicativa", en Documentos de Trabajo, Santiago de Chile: publicación digital del Centro de Estudios de la Comunicación de la Universidad de Chile, número 6, otoño de 2009, pp. 5-30.

SANGRADOR GARCÍA, José Luis: "La personalidad autoritaria", en el volumen coordinado por JIMÉNEZ BURILLO, Florencio, Psicología de las relaciones de autoridad y poder, Barcelona: Editorial UOC, 2006, p. 127-165.

SEOANE, Julio, y RODRÍGUEZ, Ángel: Psicología política, Madrid: Ediciones Pirámide, 1988.

SERRANO MAÍlLO, Alfonso, y SERRANO GÓMEZ, Alfonso: "El aumento de la firmeza en la respuesta al delito a nivel legislativo en España (1995-2007)", en KURY, Helmut, y SERRANO MAÍlLO, Alfonso (editores), Punitividad y victimización en la experiencia contemporánea. Estudios, Madrid: Dykinson, 2009, pp. 294-316.

SQUELLA NARDUCCI, Agustín: Igualdad, Valparaíso: Editorial de la Universidad de Valparaíso, 2014.

STOPPINO, Mario: voz Autoritarismo, en el Diccionario de política dirigido por BOBBIO, Norberto, MATTEUCCI, Nicola, y PASQUINO, Gianfranco, nueva edición enteramente revisada y ampliada, con redacción española de ARICÓ, José, SOLER, Martí, y TULA, Jorge, México: Siglo Veintiuno, $14^{\mathrm{a}}$ ed., 2005, t. I, pp. 125-136.

TODOROV, Tzvetan: La experiencia totalitaria, Trad. de SOBREGUÉS, Noemí, Barcelona: Galaxia Gutemberg, 2014.

VON ASTER, E.: Introducción a la Psicología, Trad. de la $2^{\mathrm{a}}$ edición alemana por LANDA, Rubén, Barcelona: Editorial Labor, $3^{\text {a }}$ ed., 1935.

VORMBAUM, Thomas: Saggi di storia del Diritto penale moderno, Napoli: Edizioni Scientifiche Italiane, 2018. 
WOLF, Werner: Introducción a la Psicología, Trad. de Pascual del Roncal, Federico, México: Fondo de Cultura Económica, 1969.

YOUNG, Kimball: Psicología social de la personalidad, versión castellana de CALDERÓN, Irma, Buenos Aires: Editorial Paidós, 1969.

ZAFFARONI, Eugenio Raúl: Derecho penal. Parte general, con la colaboración de ALAGIA, Alejandro, y SLOKAR, Alejandro, Buenos Aires: Ediar, $2^{\mathrm{a}}$ ed., 2002.

ZAFFARONI, Eugenio Raúl: Doctrina penal nazi. La dogmática penal alemana entre 1933 y 1945 , prólogo de MUÑOZ CONDE, Francisco, Buenos Aires: Ediar, 2017.

ZAFFARONI, Eugenio Raúl: Tratado de Derecho penal, Parte general, 5 vols., Buenos Aires: Ediar, t. II, 1987. 